\title{
Contratos agrarios y renta de la tierra en Toledo, 1521-1650
}

\author{
DAVId GonZÁlez Agudo
}

\begin{abstract}
PALABRAS CLAVE: renta de la tierra, usufructo, Toledo, España moderna.
\end{abstract}

\section{CÓDIGOS JEL: N13, N23, N53, Q12.}

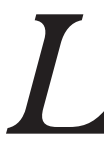

a gestión de los patrimonios del clero secular no es un asunto bien conocido en la España moderna. El objetivo de este trabajo es analizar los contratos agrarios y la evolución de la renta de la tierra sobre una muestra representativa de cincuenta propiedades rurales de la catedral de Toledo entre 1521 y 1650. El censo enfitéutico fue el contrato de cesión mayoritario, si bien la mayor fuente de ingresos procedía de los arrendamientos. Hasta mediados del siglo XVI prevalecieron los arrendamientos a largo plazo; después se expandieron las fórmulas a corto. Entre 1521-1529 y 1642-1650 la renta en las labranzas creció un 28\% y en las dehesas descendió un $57 \%$. Tal divergencia podría explicarse por un creciente diferencial de rentabilidad a favor del cultivo y por un encarecimiento de las actividades ganaderas. Sin embargo, que una parte considerable de arrendamientos fuese asumida por canónigos y élites locales pudo alterar tanto la trayectoria de la renta rústica como el tipo de contratos. Este caso condiciona el papel de la renta como variable de coyuntura económica y cuestiona si los intereses corporativos se impusieron al ideal de maximización de la renta. 


\section{Agrarian contracts and land rent in Toledo, 1521-1650}

\section{KEYWORDS: land rent, land tenure, Toledo, modern Spain.}

\section{JEL CODES: N13, N23, N53, Q12.}

$\int r^{i}$ ittle is known about the management of secular clergy assets in modern Spain. The aim of this work is to analyse agrarian contracts and the evolution of land rent in Toledo between 1521 and 1650, from a representative sample of fifty rural properties belonging to the city's Cathedral. The census was the most frequent contract, although the lease provided the main source of income for the Chapter. Long-term leases were more prevalent during the first half of the sixteenth century, after which shortterm leases increased. From 1521-1529 and 1642-1650, farmland rents increased by $28 \%$, while meadow rents fell by $57 \%$. Such a divergence can be explained by the growing profitability of farmland and increases in the cost of livestock activities. In the seventeenth century, agrarian depression in the region and reorientation of Madrid's grain supplies would have driven down the rents of the Cathedral farmlands that were closely located to the seat of the new Crown. However, the takeover of a considerable share of the leases by Chapter canons and civil elites would have altered both rent trends and contractual formulas. This makes the role of land rent a proxy for economic performance and questions the idea that corporate interests prevailed over the ideal of maximizing income.

Recepción: 2018-01-08 - Revisión: 2018-08-17 - Aceptación: 2018-09-12

David González Agudo [orcid.org/0000-0002-8917-5071] es investigador postdoctoral en la Vancouver School of Economics, University of British Columbia. Dirección para correspondencia: 258-6000 Iona Drive, V6T1L4Vancouver (Canadá).C.e.:dagoag@mail.ubc.ca; dgagudo@yahoo.es 


\section{INTRODUCCIÓN}

Este trabajo pretende realizar una aproximación a las fórmulas de cesión del usufructo de la tierra y a sus mecanismos de gestión en la provincia de Toledo durante el Periodo Moderno. La fuente primordial son las cuentas de la Catedral Primada, donde se registraba, entre otros conceptos, el monto por arrendamientos y censos de las fincas rústicas de dicha institución.

La gestión económica del patrimonio del clero, especialmente el secular, no es muy conocida en nuestro país. Además, la imagen a menudo transmitida por la historiografía es la de unas clases pasivas que vivían de los ingresos de la actividad crediticia o de los rendimientos de sus bienes, procedentes de donaciones (Catalán, 2018). Los patrimonios eclesiásticos, que se remontan a la Baja Edad Media, se consolidaron en la Edad Moderna con la expansión de las instituciones religiosas y el Estado. El estudio de este proceso de afianzamiento material cobra interés, pues implicó a factores productivos muy significativos en la vida económica preindustrial, como los inmuebles o la tierra ${ }^{1}$.

Las rentas derivadas de la tierra, por ejemplo, fueron fuentes de ingresos esenciales para el sostenimiento de la nobleza y el clero. Sebastián Amarilla (1990: 53-56) ofrece algunos datos sobre su relevancia en la España moderna: a) en Castilla, los privilegiados poseían casi dos tercios de la superficie cultivable que, en buena parte, no explotaban directamente (Fernández de Pinedo, Gil Novales \& Derozier, 1980: 55)²; b) las tierras sujetas al pago de renta suponían una proporción considerable o mayoritaria en extensas áreas del país ${ }^{3}$; c) el porcentaje de renteros fue elevado ${ }^{4}$; d) la renta solía ser la carga

1. Sobre el desarrollo del mundo agrario entre la Edad Media y la Edad Moderna, véanse BRENNER $(1976,1982,1997)$ y EPSTEIN (2000). Sobre la importancia de cuestiones sobre tenencia y transmisión de la tierra en los niveles de desarrollo económico, véase VAN BAVEL (2008b).

2. En la antigua provincia de Toledo, según el catastro de Ensenada, el estado eclesiástico poseía el 21,5\% de la superficie agraria (DoNÉZAR, 1984: 512-513). La renta de la tierra era una de las principales fuentes de ingresos para la nobleza y el clero. Para el alto clero secular, obispos y cabildos, los diezmos eran, con diferencia, la principal fuente de ingresos (BARRIO, 2004). No era así en Sigüenza (Guadalajara), en cuanto a los ingresos en especie. No obstante, es probable que, considerando los ingresos en dinero, las dos contribuciones respectivas de rentas y diezmos resultasen más equilibradas (GonZÁlez Agudo, 2011).

3. Estas magnitudes, además, tendieron a aumentar entre finales del siglo xv y los inicios del siglo XIX (GARCía SANZ, 1985: 650-651).

4. En Castilla y León los agricultores arrendatarios casi doblaban en número a los propietarios de tierras hacia 1797 (RoBLEDO, 1984: 74). En Salamanca, Zamora y León la proporción de arrendatarios superaba el 50\% (SEBASTIÁN AMARILLA, 1990: 53). En Palencia, el número de renteros era más del doble que el de labradores propietarios (MARCOS, 1985: 41). En Ávila, los arrendatarios cuadruplicaban a los labradores propietarios (CUERVo, 2006: 11). El censo de Godoy de 1797 recuenta, 
más onerosa para los cultivadores directos y podía suponer más del $20 \%$ del producto agrícola bruto (Marcos, 2000: 425-426) ${ }^{5}$; e) rentas y otros derechos sobre la tierra generaban, anualmente, gran volumen de cereal que entraba en los circuitos comerciales y en el aprovisionamiento urbano ${ }^{6}$; f) las fluctuaciones del peso relativo de la renta sobre el producto agrario tanto podían obstaculizar el crecimiento, contribuyendo incluso a fases de recesión ${ }^{7}$, como coadyuvar a la recuperación de cultivos y producciones ${ }^{8}$; y g) la negociación contractual fue una de las mayores expresiones de las relaciones económicas y sociales en el campo castellano moderno.

En Europa, la peste y las crisis del siglo XIV causaron una inmediata contracción del área cultivada, que repercutiría en una caída importante del producto agrario. Los señores feudales y propietarios de tierras afrontaron un descenso considerable de rentas y derechos, además de un alza de salarios a sus jornaleros. Las respuestas fueron diversas: una fue renunciar a la agricultura y dedicar los campos abandonados a pastos; otra fue ceder el usufructo de las tierras a terceros mediante contratos de larga duración.

La salida de las crisis del siglo XIV fue relativamente precoz en Castilla, lo que permitió la recuperación poblacional y la reanudación del proceso colonizador desde 1420-1430. El crecimiento demográfico propició, merced al alza de la demanda de alimentos, la paulatina reocupación de las tierras abandonadas (Sebastián Amarilla, 2005). El arrendamiento, que permitía actualizar la renta, irrumpió en el siglo XV en algunos dominios eclesiásticos y se expandiría en detrimento de la enfiteusis ${ }^{9}$. El arriendo sería habitual en Castilla, Andalucía, Extremadura y en el País Vasco durante la Edad Moderna (Marcos, 2000).

para los territorios de la antigua provincia de Guadalajara, 3.469 labradores propietarios, 8.988 arrendatarios y 7.202 jornaleros. En Castilla la Nueva el recuento fue de 30.504 labradores propietarios, 38.874 arrendatarios y 93.203 jornaleros. Los datos son el resultado de la suma de las antiguas provincias de Cuenca, Guadalajara, Madrid, La Mancha, Toledo y el Real Sitio de Aranjuez (INE, 1992). Muchos pequeños propietarios también eran, a la vez, arrendatarios.

5. Blázquez Garbajosa (1988: 275-277) cita las actas de las Cortes de Madrigal (1438), según las cuales las rentas en especie solían ser, como mínimo, del orden de veinte fanegas sobre cien fanegas cosechadas.

6. Hasta el establecimiento de la Corte madrileña en 1561, el espacio agrario toledano estuvo profundamente marcado por la trayectoria de la demanda de la ciudad de Toledo, ligada a sus vaivenes demográficos.

7. Así parece haber ocurrido en zonas del valle del Duero a finales del siglo XVI (YUN, 1985: 8; SEBASTIÁN AMARILLA, 1990: 55).

8. Así sucedió en la España interior durante la segunda mitad o el último cuarto del siglo XVII (SEBASTián Amarilla, 1990: 55).

9. Véase García SANZ (1977). En el monasterio de Santa María de Sandoval (León) el arrendamiento se tornó predominante hacia la década de 1480 (SEBAstián AMARILla, 1992: 718-720). 
En las últimas décadas, algunas investigaciones internacionales han retomado la reconstrucción de series de renta de la tierra, el estudio de las fórmulas contractuales y su evolución en el tiempo ${ }^{10}$. Sin embargo, el análisis de la renta como indicador de coyuntura agraria y económica se ha impuesto a su estudio como parte de los mecanismos de gestión y consolidación de los patrimonios eclesiásticos ${ }^{11}$.

En la España moderna y, más en concreto, en Castilla, los trabajos más abundantes se refieren a la submeseta norte. También, buena parte de ellos tiene como fin último el análisis clásico de la renta de la tierra ${ }^{12}$. De entre los que cubren todo o parte del siglo XVI, la mayoría destaca un alza de la variable. No obstante, dentro de esa tendencia general hay movimientos particulares que, por responder a circunstancias locales, motivan el estudio de la gestión de los patrimonios eclesiásticos rurales.

Analizar el caso toledano interesa por varias razones: a) por la relevancia de la Ciudad Imperial en la Castilla moderna; b) por la relativa escasez de estudios en su territo-

10. Entre los trabajos europeos más tempranos, cabe citar el de LE RoY LADURIE (1966), sobre la región francesa de Languedoc, CANCILA (1978), sobre Sicilia, y BRUMONT (1984), sobre Castilla la Vieja.

11. Sobre la relación renta de la tierra-productividad agraria en los siglos XVII y XVIII europeos, véase Allen (1988). Para Inglaterra y Gales entre 1500 y 1914, ClARK (2002). ORMROD, GibSON y LyNE (2011) reconstruyen series de rentas urbanas y agrarias en Kent, Essex y Londres entre 1580 y 1914. Para los entornos de París entre 1450 y 1815, HofFman (2000). Sobre la productividad agraria en Westfalia (Alemania) entre 1600 y 1900, BRACHT (2011). Sobre fórmulas de cesión a corto plazo en los Países Bajos, Flandes y otras partes de Europa noroccidental, VAN BAVEL (2008a, 2008b), SoENS y THOEN (2008) y VERVAET $(2012,2013)$. Sobre fórmulas de cesión y derechos de propiedad en la Suecia moderna, Wästfelt (2013). Sobre los mercados de la tierra en China en los periodos tardoimperial y republicano, Pomeranz (2008). Sobre el impacto de la tecnología agrícola en las formas de tenencia en la China preindustrial, YANG (2012).

12. Sobre varias localidades de Castilla la Vieja y León en el siglo XVIII, véase ANES (1970). Sobre Segovia entre los siglos XVI y XIX, García SANZ (1977). Sobre Burgos en el siglo XVI, BRUmONT (1984). Sobre Zamora durante el Antiguo Régimen, ÁlvAREZ VÁZQUEZ (1987). Sobre el oriente leonés en la Edad Moderna, SEbastián Amarilla (1990, 1992). Sobre Ávila en los siglos XVI-XVII, Cuervo (2006). Algunas series de rentas, entre 1565 y 1800, de tierras cerealistas del Monasterio de El Escorial repartidas en municipios de Segovia y Ávila, en SÁNCHEZ MECo (1985). Sobre Ciudad Real y Almagro entre 1561 y 1700, LóPEZ-SALAZAR (1986). Sobre dehesas maestrales de la orden de Calatrava, LóPEZ-SALAZAR (1987: 54) y YUN (2004: 210). Sobre la zona de Sigüenza (Guadalajara), GonZÁlez Agudo (2011). AguAdÉ (1982) analizó la evolución de la renta de la tierra en Asturias durante el siglo XIII. LLOPIS (1991) estudió las rentas de las dehesas del monasterio de Guadalupe en el siglo XVI. Ponsot (1986) ofrece series de rentas sobre explotaciones agrícolas en la Baja Andalucía desde el siglo XVI al XIX. YUN (2004) elaboró, sobre datos de CoRONAS (1994), una serie de rentas de sembradíos de la catedral de Jaén entre 1500 y 1700. López EsTUDILLo (2007) aporta datos sobre el arrendamiento de latifundios de la catedral de Córdoba entre 1700 y 1840.Y más recientemente, GONZÁLEZ MARISCAL (2013) ha examinado la evolución de las rentas rústicas de la catedral sevillana en la Edad Moderna. 
rio circundante; c) porque las fuentes permiten arrancar en el siglo XVI, cuando otras, o bien cubren una pequeña parte de la centuria o bien comienzan en la siguiente; y d) por la poca atención que la catedral toledana ha suscitado entre historiadores económicos e institucionales, a pesar de su preeminencia histórica (Fernández Collado, 1999; Sánchez González, 2000). Prueba de esto último es la escasez de publicaciones al respecto ${ }^{13}$. La más próxima a la materia y época de este trabajo es de López Celada (1980), que estudió la evolución de las rentas del cabildo catedralicio entre 1575 y 1599. Los datos quinquenales que ofrece son interesantes, pero abarcan múltiples conceptos ${ }^{14}$.

Tras esta introducción se analizan las fuentes primarias. El tercer epígrafe continúa con la descripción, localización y clasificación de las distintas propiedades rústicas de la muestra. En el cuarto se determinan las diferentes fórmulas de cesión. En el quinto apartado se plantean algunos rasgos de la estrategia de gestión de las tierras. El sexto ofrece datos sobre la identidad y posición social de los usufructuarios. Por último, se comenta la trayectoria marcada por las series de renta.

Como veremos, las limitaciones de la documentación capitular no nos permitirán acercarnos tanto a quienes cultivaban directamente las tierras. Esto sucede especialmente con las rentas más cuantiosas para el cabildo, es decir, las obtenidas por la cesión de grandes heredamientos y posesiones. No obstante, este intento permitirá conocer mejor la evolución de las formas de cesión y la gestión del patrimonio rústico de la Catedral Primada.

\section{FUENTES}

Las cuentas de la catedral toledana ofrecen grandes posibilidades para aproximarnos a la gestión de su patrimonio ${ }^{15}$. La mayor parte de ellas correspondían al refitor, órgano ad-

13. IZQUIERDO (1980) trabajó sobre composición, rentas territoriales y modos de explotación del patrimonio rural del cabildo catedralicio de Toledo durante el siglo XIV. Sin embargo, el estudio es limitado y sólo abarca una parte de la Baja Edad Media. Posteriormente, DonÉZAR (1984: 424, 461), a través del catastro de Ensenada, ofreció cifras puntuales sobre el producto de alquileres para actividades agropecuarias en la antigua provincia. MONTEMAYOR (1996: 195-199) dedica, en una de sus obras sobre Toledo, un breve apartado a la renta de la tierra, a las formas de explotación territorial y a los contratos agrarios durante el siglo XVI. Por último, Fernández Collado (2005), en sus Rentas del clero, analiza los medios de vida del clero de la archidiócesis de Toledo durante el Trienio Constitucional, pero no incluye series de rentas.

14. También se incluyen licencias, aniversarios, almojarifazgos, las tercias de Montalbán, préstamos, beneficios, el quintillo de Maqueda y rentas decimales (López CELADA, 1980: 24-56).

15. También para reconstruir y estudiar variables de coyuntura económica. De ello dan cuenta dos trabajos sobre la producción cerealista en el arzobispado (LÓPEZ-SALAZAR \& MARTíN GALÁN, 1981; 
ministrador de los bienes del cabildo. El canónigo refitolero solía monitorizar los arrendamientos y censos de las propiedades capitulares ${ }^{16}$ y plasmarlo en varios tipos de libros ${ }^{17}$. Esta investigación se centrará en dos: la carta cuenta y las posesiones.

La carta cuenta es la fuente de información básica y ofrece, desde 1489, cifras anuales sobre arrendamientos y $\operatorname{censos}^{18}$. Los libros se dividen en ingresos (cargo) y gastos (descargo). El cargo es el que aporta información sobre el importe de arrendamientos o censos y, frecuentemente, la identidad de los tomadores. Al finalizar cada contrato suelen registrarse bastantes detalles del siguiente: nombre, oficio y vecindad del nuevo tenedor y sus fiadores; comienzo y duración del nuevo contrato; y el monto, pagadero por tercios en enero, mayo y septiembre ${ }^{19}$. Las hojas finales ofrecen la suma de ingresos, a la que se añaden deudas viejas, atrasadas o importes extraordinarios.

Por su parte, las posesiones son inventarios que permiten controlar, cada cierto tiempo, el orden sucesorio de los usufructuarios y los cambios en los contratos ${ }^{20}$. Estos libros, en cambio, suelen carecer de datos sobre extensión, localización y aprovechamiento de las tierras. La escasez de fondos sobre deslindes obliga a recurrir a fuentes alternativas ${ }^{21}$. Una es un Manual de Oficios y Cargos de 1542, donde se cita la extensión de la mayoría de las propiedades ${ }^{22}$. Otra opción son los llamados protocolos, que recogen los contratos de cesión $^{23}$. También son útiles las informaciones recogidas en los Cartularios de Toledo ${ }^{24}$.

Asimismo, el catastro de Ensenada ha servido para conocer las diferentes unidades de superficie y para complementar las fuentes anteriores ${ }^{25}$. Los libros de haciendas ofrecen,

SEBASTIÁN AmARILla et al., 2008).

16. El refitor ejercía muchas otras funciones de gestión económica (Lop, 2002, 2016).

17. Los más importantes son los de posesiones, gallinas, granero, vestuarios, cargo y data, carta cuenta, manual y mayor (TORROJA, 1977: 11).

18. Archivo y Biblioteca Capitulares de Toledo (ABCT), Obra y Fábrica, Carta Cuenta, 1.1941.234. La signatura de los libros correspondientes al siglo XVII coincide con el año que tratan. Sólo faltan los correspondientes a 1540-1541 y 1631-1632.

19. También había una parte del importe en gallinas, abonada el día de Todos los Santos.

20. ABCT, Obra y Fábrica, Posesiones, 977-1.044. Aunque la serie comienza en 1354, desafortunadamente no existen volúmenes anuales.

21. Tan sólo existen dos libros: uno sobre deslindes de heredades en Cobeja y Alameda de La Sagra, de 1381; y otro sobre propiedades urbanas, para 1491 y 1492 (TORROJA, 1977: 132-133).

22. ABCT, Obra y Fábrica, Oficios y Cargos, 909. «Libro manual de las cosas que son cargo de los ministros del cabildo y como se arriendan sus posesiones».

23. ABCT, Obra y Fábrica, Protocolos.

24. HERNÁNDEZ (1985).

25. Archivo Histórico Provincial de Toledo (AHPT), Catastro de Ensenada. Dentro del arzobis- 
para el sigo XVIII, superficies de diecisiete posesiones de la muestra ${ }^{26}$, lo que permite calcular el incremento superficial promedio $(7,8 \%)$ entre el siglo XVI y el XVIII ${ }^{27}$. Esta variación sirve para estimar la extensión de posesiones que carecen de datos para el siglo XVI. No obstante, apenas siete propiedades han requerido este ejercicio ${ }^{28}$.

El refitor expresaba los importes de arrendamientos y censos en moneda corriente y gallinas, siendo la proporción habitual dos aves por cada quinientos maravedíes ${ }^{29}$. El cobro en gallinas parece tener dos motivos prácticos: a) protección contra los efectos de la inflación y de las manipulaciones monetarias, especialmente en las cesiones a largo plazo; y b) unidad de cuenta para compensar gastos e ingresos en los balances capitulares $^{30}$. En cuanto a la percepción de rentas en dinero, esta ya se daba en la segunda mitad del siglo XIV (Izquierdo, 1980) y se ha observado en otras instituciones religiosas toledanas $^{31}$, así como también en ciudades del sur peninsular ${ }^{32}$. En cambio, en la submeseta norte y otras zonas castellanas la percepción de rentas parece haberse decantado por el grano, al menos en las tierras de labor ${ }^{33}$.

pado de Toledo se utilizaban medidas de superficie diferentes. Sobre conversión de antiguas unidades al sistema métrico decimal, véase Сово (1991: 38-39).

26. AHPT, Catastro de Ensenada, Libros de haciendas del estado eclesiástico. Se ha podido cotejar la superficie de las siguientes propiedades muestrales entre los siglos XVI y XVIII: Hurtada, Porti1lo, Regachuelo de Canales, Mazaraveda, Mazarracín, Matamoros, Valdecubas, Higueruela, Yeles, Yuncler, Azaña, Algurilla, Añover, Arcicóllar, Canales, Lucillos y Olías del Rey.

27. De las diecisiete propiedades examinadas, quince aumentaron su superficie entre el siglo XVI y el XVIII. Tan sólo dos de ellas, Portillo y Matamoros, vieron mermada su extensión entre ambas centurias.

28. Las propiedades son Benquerencia, Canillas, Ablates y Malagoncillo, Ablatejos, Montalbanejos, Santa Olalla y la huerta del Capiscol.

29. Parte de las rentas del refitor se recibía en gallinas que, después, se distribuían entre los miembros del cabildo (LÓPEZ CELADA, 1980: 17). En unas pocas posesiones se recibían, además, varias fanegas de pan quizá relacionadas con el arrendamiento de derechos señoriales. Se trata de los señoríos de Villeriche, Canillas, Azaña, Esquivias y Yeles. Los libros de gallinas contienen cuentas desde 1460 hasta 1585 (TORROJA, 1977: 150).

30. Una parte de las rentas urbanas de la catedral también se percibía en gallinas (DreLichman \& GonZÁlez Agudo, 2014).

31. El monasterio de Santo Domingo el Real utilizaba el mismo modo de percepción de rentas que la catedral en sus propiedades rústicas y urbanas. Archivo Histórico Nacional (AHN), Clero, Libro 15518.

32. La catedral de Jaén solía estipular los arrendamientos en dinero y gallinas para las viñas, huertas y olivares. En grandes superficies de cereal, donadíos y cortijos se prefería el grano (CoRONAS, 1994: 249). En Sevilla, los arrendamientos de fincas catedralicias solían constar de un montante principal en moneda y otro secundario en gallinas (GonZÁlez MARISCAL, 2008: 8).

33. Entre los siglos XVI y XIX, la catedral de Segovia recaudó los arrendamientos de sus tierras de pan llevar en especie y sólo cobraba la renta de los prados en dinero (GARCía SANZ, 1977:300). En Ávila, buena parte de las rentas del cabildo catedralicio eran recaudadas en grano (CUERVo, 2006: 15). En 
Algunos autores han justificado la preferencia toledana por el recaudo en moneda corriente debido al gran volumen de diezmos percibidos en especie ${ }^{34}$; argumento que no parece convincente ${ }^{35}$. Otros aducen que esta elección presupone un desarrollo considerable del comercio, de la industria urbana y de la producción mercantil; de modo que las rentas en dinero se pagaban sobre tierras cuyos productos se destinaban a la venta ${ }^{36}$. Aún pueden añadirse otros motivos: uno sería la huida capitular de los elevados costes de recogida y comercialización del grano recaudado; otro tendría relación con la inmunidad histórica de la Iglesia en la libre circulación y venta de granos. En ambos casos los canónigos evitarían posibles fricciones con las élites civiles urbanas al comercializar el cereal $^{37}$.

\section{PROPIEDADES RURALES}

La documentación catedralicia permite considerar una muestra de cincuenta propiedades rústicas repartidas en cuarenta lugares de Toledo que, entre 1520 y 1650, mantuvieron su integridad ${ }^{38}$. Estas posesiones pasaron al patrimonio capitular mediante donaciones, compras o permutas. La catedral, propietaria plena de las tierras, cedía su dominio útil a los usufructuarios a cambio de una renta. Estas operaciones se estipula-

León, el monasterio de Sandoval percibía en grano las rentas de sus heredades (SEBASTIÁN AmARILLA, 1990). Igualmente lo hacía el cabildo catedralicio de Zamora (ÁlvAREZ VÁzQUEZ, 1987). En Sigüenza, la mayoría de las propiedades rústicas de la catedral, principalmente heredades de tierras de pan llevar, se cedían a pan en trigo y cebada (GonZÁlez AGUDO, 2011). En el siglo XVIII, el cabildo de Valladolid tenía preferencia por la renta en especie (AMALRIC, 1985: 225). En la Galicia moderna, los patrimonios de los monasterios se evaluaban en rentas en especie (SAAVEDRA, 2018).

34.MONTEMAYOR (1996: 195).

35. Los vestuarios, pese a aparecer en especie, no reflejan los diezmos recaudados directamente por el cabildo catedralicio, sino, en realidad, diezmos arrendados. Los canónigos recibían los diezmos en metálico (SEBASTIÁN AmARILla et al., 2008: 7).

36. BRumont (1984: 30). La renta pagada en moneda puede ser un indicador del alto grado de comercialización agrícola en la zona de investigación, algo que se espera cuando existen grandes arrendatarios (VAN BAVEL, 2001).

37. Sobre la inmunidad eclesiástica en la comercialización de los granos y los conflictos con las élites locales en Zamora, véase Álvarez VÁzQuEZ (1987: 123-137).

38. Para homogeneizar la muestra, he procurado descartar las propiedades que pasaron a formar parte del patrimonio catedralicio después del 1 de enero de 1520 , las que se enajenaron de él antes del 31 de diciembre de 1650 o las que fueron modificadas durante ese intervalo. Así, de 77 bienes rústicos se han eliminado diecisiete, en su mayoría, de pequeña superficie: dos tierras en Ajofrín, una heredad en Carpio de Tajo, una tierra y unos badenes en Mazarracín, un huerto y una viña en Solanilla, dos huertos en el paraje de Huertas, una heredad en La Fuente, una tierra en Darrahiel, una tierra en Arcicóllar, una heredad en Albalá, otra en Olías del Rey, una viña en Pedrosilla, una tierra en Valdemozárabes y una heredad de la capilla de Gil de Rojas. 
ban mediante contratos. Así, para cada año y propiedad es posible registrar la modalidad, la duración teórica, la fecha de comienzo, la identidad del tomador y el importe.

Entre 1521 y 1650 las rentas de la muestra supusieron entre un $16 \%$ y un 34\% sobre el total de ingresos de la carta cuenta. Es preciso advertir de que algunas van ligadas a derechos señoriales ${ }^{39}$ cuya recaudación podía ser también arrendada ${ }^{40}$. Así, rentas territoriales y señoriales se incorporaban en una única cantidad. Esto impide, a veces, distinguir el monto de cada concepto, lo que hace engrosar ligeramente la cantidad final percibida por rentas territoriales ${ }^{41}$. Este fenómeno, que no parece ser exclusivo de Toledo ${ }^{42}$, sucede en posesiones tituladas como señorio, heredamiento y señorio, o dehesa, término y señorío.

La muestra se distribuye, geográficamente, por las actuales comarcas de La Sagra y Torrijos, y por los contornos de la ciudad, donde la concentración es relativamente alta (González Agudo, 2017). La cercanía al lugar habitual de residencia de los canónigos facilitaba la gestión y la supervisión. Además, las heredades capitulares solían situarse en

39. El cabildo ejercía el señorío en: Ajofrín; Valdecubas con Azucaica, Mazarracín y Zalencas; Algurilla; Alpuébrega; Arcicóllar; Benquerencia; Cobeja y Alameda; Canillas; Esquivias; Higueruela; Hovaniel; Lucillos; Azaña; Mazaraveda; Olías;Villeriche;Villamiel; Renales y Villamocén;Yeles; y Yuncler. En la mayoría, el dominio capitular era solariego, a excepción de Ajofrín, donde derivaba de la administración de justicia. Allí se pagaba, entre otras cosas, el derecho de los humos, consistente en un doceavo de la cosecha del pan, siempre que esta llegase a doce fanegas (LÓPEZ CELADA, 1980: 89). Cabe advertir que, en otras propiedades tituladas como señorío, este no era ejercido por el cabildo, sino por el arzobispo de Toledo, como en Añover o Canales.

40. Para Illescas, Villeriche, Esquivias, Canillas, Yeles o Azaña existen cuantías en el libro del granero que podrían corresponder a ciertos derechos señoriales o al arrendamiento de su recaudación. Por ejemplo, en Illescas el cabildo no poseía fincas arrendadas, pero percibía 195 fanegas de pan en razón del señorío, en 1587 y 1599. En el también señorío de Esquivias se pagaban, en esos años, cien fanegas de trigo y cien de cebada; allí sí había propiedades arrendadas en metálico. En Yeles se percibían, por derechos señoriales, siete maravedíes por fanega de trigo y seis por fanega de cebada; estos parecían arrendarse por sesenta fanegas de pan. ABCT, Obra y Fábrica, Refitor, Granero, 506, 519. Estas cuantías, relativamente exiguas, no se incluyen en la muestra porque su procedencia es desconocida.

41. Sólo ha podido prescindirse de la parte señorial de las rentas cuando esta se especificaba.

42. En algunas comarcas catalanas es casi imposible diferenciar, del total de ingresos, la parte correspondiente a la renta de la tierra (DURÁn I PUJOL, 1985: 28). En Galicia, el foro va más allá de la simple relación que supone la estipulación de una renta, implicando el reconocimiento de señorío y exigiéndose, ya en plena Edad Moderna, ciertas prestaciones y cargas adicionales de origen medieval (SAAVEDRA, 1990: 145). En el oriente leonés, la pervivencia del fuero expresaba una condición de tributo-renta y una vinculación que trascendía el mero usufructo (SEBASTIÁN AMARILLA, 1999). En la Valencia del siglo XVI, las rentas feudales del marquesado de Llombai incluían censos y luismos, particiones, prestaciones personales o azofras y monopolios (ARDIT, 2006: 23). En Flandes, los usufructuarios de grandes propiedades rústicas del hospital de San Juan de Brujas pagaban por el terrazgo y por derechos señoriales relacionados con él, como los diezmos de la zona (VERVAET, 2012). 
los lugares de mayor influencia religiosa y social ${ }^{43}$. Esta aglutinación implica una estrategia económica consistente en formar unidades compactas y cercanas a la capital; ya fuera ampliando las tierras recibidas o incorporando nuevos implantes territoriales (Pastor de Togneri, 1975).

\author{
MAPA 1 \\ Distribución de la muestra de posesiones rústicas \\ del cabildo catedralicio de Toledo en su actual provincia
}

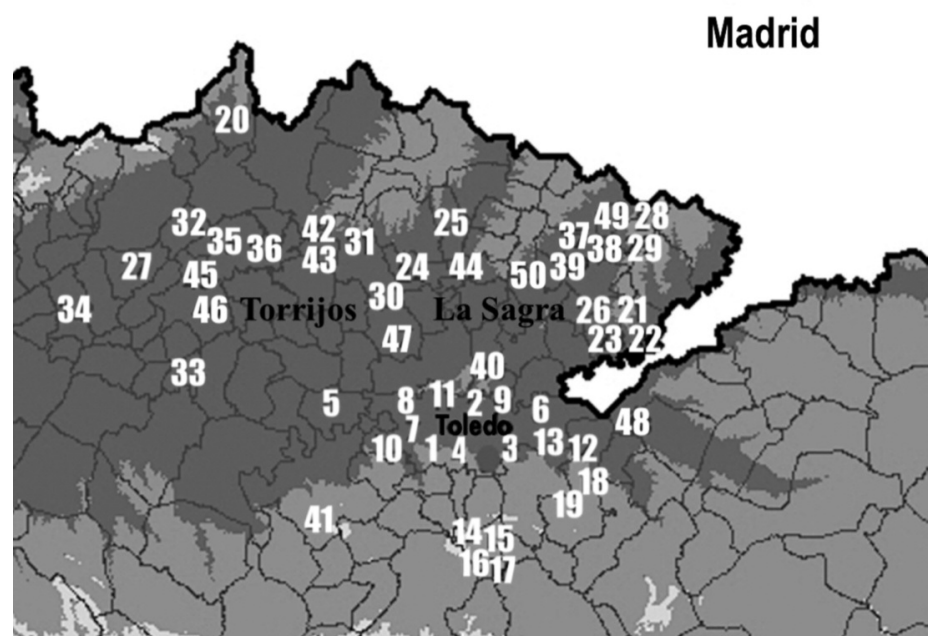

1) Viña-tejar de Alcardete; 2) huerta de Alaytique; 3) dehesa de Valdecubas; 4) tierras en Albalá; 5) 4 yugadas en Albalá; 6) dehesa de Benquerencia; 7) dehesa de Canillas; 8) dehesa de Mazaraveda; 9) dehesa de Mazarracín; 10) dehesa de Matamoros; 11) huerta del Capiscol; 12) dehesas de Ablates y Malagoncillo; 13) dehesa de Ablatejos; 14) señorío de Ajofrín (viña del Olmedo); 15) tierras y viñas de Ajofrín; 16) huerta de los Baños; 17) huebras y prados de los caballos; 18) dehesa de Valdemozárabes; 19) dehesa de Montalbanejos; 20) Almorox; 21) mitad de heredad en Añover; 22) otra mitad de heredad en Añover; 23) yugada de Constanza Hernández de Quirós; 24) heredamiento y señorío de Arcicóllar; 25) dehesa de Regachuelo de Canales; 26) señoríos de Cobeja y Alameda, y dehesa de Darageval; 27) heredamiento de Miguel Martín; 28) heredamiento de Santa María de las Candelas; 29) señorío de Esquivias (tierras); 30) heredamiento y señorío de Algurilla; 31) heredamiento y señorío de Renales y Villamocén; 32) heredamiento y señorío de Hovaniel; 33) heredamiento de Hurtada; 34) heredamiento de Lucillos; 35) heredamiento de Fuente Altamia; 36) heredamiento de Gil de Rojas; 37) heredamiento y señorío de Azaña; 38) heredamiento de Azaña (viñas); 39) dehesa, término y señorío de Villeriche; 40) heredamiento y señorío de Olías; 41) dehesa, término y señorío de Alpuébrega; 42) heredamiento de Portillo; 43) olivas de Portillo; 44) heredamiento y señorío de Canales; 45) heredamiento y señorío de Higueruela; 46) heredamiento de Santa Olalla; 47) heredamiento y señorío de Villamiel; 48) heredamiento de Melgar; 49) tierras y señorío de Yeles; 50) heredamiento y señorío de Yuncler.

Fuente: ABCT, Obra y Fábrica, Posesiones y Protocolos.

43. GARCía SANZ et al. (1981: 44). En Castilla la Nueva se ha observado también un alto grado de concentración en torno a la sede capitular en las propiedades rurales de la catedral de Sigüenza (GoNZÁlEZ Agudo, 2011). 
La extensión total de la muestra supera las quince mil hectáreas (Anexo 1$)^{44}$, de la que casi la mitad (49,3\%) estaba en el actual término municipal de Toledo. Resulta llamativo el tamaño medio (385 ha) y mediano (149 ha) de las posesiones: cinco superaban las mil hectáreas; veintidós superaban las cien hectáreas; y sólo siete tenían menos de diez. La gran superficie se explica por una presencia abrumadora de pasturas: las dehesas ocupaban más del $80 \%$ de la extensión muestral. Conviene precisar que una pequeña parte de estas -cuya medición no figura- se labraba ${ }^{45}$. Por su parte, la superficie de cultivos (tierras, viñedos, olivares y huertas) es minoritaria (17,2\%). Estos se hallaban, principalmente, en la franja septentrional (La Sagra-Torrijos).

\section{FÓRMULAS DE CESIÓN}

El Cuadro 1 agrupa las fórmulas de cesión de todas las propiedades rústicas de la catedral hacia $1611^{46}$. El censo o tributo infiteosyn era mayoritario y suponía casi un $87 \%$ de las posesiones en la carta cuenta. Es una fórmula a perpetuidad muy antigua ${ }^{47}$, que simbolizaba el reconocimiento del dominio eminente del cabildo sobre la propiedad. Los tributos aluden, en general, a posesiones relativamente pequeñas en los entornos de Toledo. La superficie media de 131 propiedades acensuadas que han podido identificarse apenas rebasaba las dos hectáreas. La mayoría de ellas eran viñedos ${ }^{48}$.

Para el cabildo, el importe del censo era fijo y, por tanto, su valor real se veía afectado por la inflación. Por eso, el monto de todos los tributos suponía una parte minoritaria en

44. No ha sido posible hallar la superficie de nueve propiedades: huerta de Alaytique, tres pertenencias en Ajofrín, una en Arcicóllar, una en Albalá, una en Añover, una en Azaña, y la dehesa de Villeriche.

45. Esta fórmula se denominaba dehesa de pasto y labor y se ha observado también en Talavera de la Reina (SUÁReZ ÁlvareZ, 1982: 133 y ss.) y Plasencia (LADERO, 1982: 178-179). El cabildo solía prohibir el cultivo de partes rotas durante los últimos tres años del contrato. El último año debían dejarse libres, como mínimo, la mitad de los labrantíos para que los nuevos usufructuarios entrasen a barbechar. Así sucedía, por ejemplo, en las dehesas de Benquerencia, Canillas o Valdemozárabes. En tan sólo tres dehesas de la muestra (Matamoros, Alpuébrega y Regachuelo de Canales) el uso silvopastoril es citado como forma exclusiva de explotación. AHPT, Obra y Fábrica, Posesiones, Manual y Protocolos.

46. Aparte de la catedral, estas fórmulas fueron utilizadas por otros grandes propietarios de la ciudad, como el monasterio de Santo Domingo el Real (BARRIOS, 1997).

47. El censo ya aparece a principios del siglo XIII en la documentación capitular (HERNÁNDEZ, 1996).

48. Estas propiedades estaban en Alcardete, Barro, Ajofrín, Arcicóllar, Alcalá, Benhalavia, Zalencas, Fontalba, Azaña (Numancia de la Sagra), Vallehermoso y el Mármol, Olías del Rey, Pedrosilla, Valdelcid, Villamiel de Toledo, Yeles y Burguillos de Toledo. La extensión media de estas posesiones era de 2,20 hectáreas. 
los ingresos del refitor (en torno al 7\% del total) en concepto de cesión del usufructo de sus propiedades rústicas. En cambio, el censatario podía transferir el tributo a otra persona, recibiendo de esta el valor corriente de la propiedad. El «vendedor» solía pagar al cabildo el alicer, que era el diezmo del precio de la operación ${ }^{49}$.

Reconstruir el valor real de las posesiones acensuadas requeriría conocer los precios de venta de los censos o, al menos, disponer de registros completos de aliceres. Estas razones, más las lagunas en la documentación, obligan, por tanto, a descartar de la muestra estas propiedades y a orientar la atención sobre las arrendadas.

\section{CUADRO 1}

Tipos de cesión de las propiedades rústicas de la catedral toledana, 1611

\begin{tabular}{lcrrrrr}
\hline $\begin{array}{l}\text { Modalidad } \\
\text { de cesión }\end{array}$ & $\begin{array}{c}\text { Número } \\
\text { propiedades }\end{array}$ & $\begin{array}{c}\% \\
\text { total }\end{array}$ & $\begin{array}{c}\text { Importe } \\
\text { maravedíes }\end{array}$ & $\begin{array}{c}\text { Importe } \\
\text { gallinas }\end{array}$ & $\begin{array}{c}\% \text { total } \\
\text { mrs }\end{array}$ & $\begin{array}{c}\% \text { total } \\
\text { gallinas }\end{array}$ \\
\hline Censo o tributo & 461 & 86,82 & $294.924,5$ & 785 & 7,32 & 6,17 \\
\hline Juro & 1 & 0,19 & $4.000,0$ & 0 & 0,10 & 0,00 \\
\hline Una vida & 10 & 1,88 & $46.000,0$ & 186 & 1,14 & 1,46 \\
Dos vidas & 2 & 0,38 & $40.480,0$ & 162 & 1,00 & 1,27 \\
Tres vidas & 7 & 1,32 & $44.452,0$ & 166 & 1,10 & 1,30 \\
Arrendamiento a I/p & 19 & 3,58 & $130.932,0$ & 514 & 3,25 & 4,04 \\
\hline 4 años & 1 & 0,19 & $23.000,0$ & 0 & 0,57 & 0,00 \\
6 años & 2 & 0,38 & $54.554,0$ & 0 & 1,35 & 0,00 \\
8 años & 1 & 0,19 & 0,0 & 0 & 0,00 & 0,00 \\
9 años & 42 & 7,91 & $3.460 .992,5$ & 11.404 & 85,89 & 89,56 \\
Arrendamiento a c/p & 46 & 8,66 & $3.538 .546,5$ & 11.404 & 87,82 & 89,56 \\
\hline Sin datos & 4 & 0,75 & $61.024,0$ & 30 & 1,51 & 0,24 \\
\hline Total & $\mathbf{5 3 1}$ & $\mathbf{1 0 0 , 0 0}$ & $\mathbf{4 . 0 2 9 . 4 2 7 , 0}$ & $\mathbf{1 2 . 7 3 3}$ & $\mathbf{1 0 0 , 0 0}$ & $\mathbf{1 0 0 , 0 0}$ \\
\hline
\end{tabular}

Fuente: ABCT, Obra y Fábrica, Carta Cuenta, 1611.

En Toledo pueden distinguirse arrendamientos a largo y a corto plazo. Los largos podían durar de una a tres vidas. El contrato ad vitam se solía estipular por la vida del arrendatario, si bien este podía designar a otro. El arrendamiento por dos vidas solía convenirse por las del tomador y su cónyuge, confiriendo al último un derecho de supervivencia. Finalmente, los contratos por tres vidas se acordaban por las del arrendatario, el cónyuge y un descendiente que podía ser designado después. En los arrendamientos largos la renta no se actualizaba en tanto permaneciese el derecho de tenencia. El contrato expiraba al

49. Apenas existen, incompletos, dos libros de aliceres para 1587-1623. ABCT, Obra y Fábrica, 361 y 362 . 
fallecer la última persona a cuya vida estaba sujeto el derecho o al abandonarse voluntariamente el contrato (dejamiento).

Entre 1521 y 1650 los arrendamientos a largo plazo llegaron a afectar a treinta y cinco propiedades de la muestra. En veintitrés posesiones se aplicó el contrato ad vitam y en trece el de tres vidas, si bien en dos de estas últimas se acabaría optando por el de una vida. La fórmula de dos vidas aparece temporalmente en una sola posesión. La duración efectiva media de los arrendamientos a largo rondaba los veintiocho años. Un 30\% del total oscilaba entre los veintiuno y los cuarenta años; el 25,5\% duraba entre once y veinte años; el $17 \%$ lo hacía entre el primero y el quinto año; y un 15\% entre seis y diez años. Los contratos superiores a cuarenta años fueron minoritarios $(12,8 \%)$. De esta clasificación se infiere que casi un tercio $(31,9 \%)$ de los arrendamientos a largo se rescindían antes de cumplir diez años. Esta renovación permitía a los canónigos toledanos tener actualizada la renta de una parte significativa de sus heredades rústicas.

El Gráfico 1 muestra que el arrendamiento mayoritario entre 1521 y 1650 fue el de corto plazo. Esta modalidad se llegó a emplear en cuarenta y ocho posesiones. De un total de 615 contratos examinados, 531 (un 86,3\%) eran cesiones a corto inferiores a diez años. El contrato por nueve años fue el preferido y figura en 457 documentos ${ }^{50}$. Para los labrantíos solía establecerse, según costumbre, la rotación bienal o año y vez. El último año del contrato la mitad de las tierras debían dejarse libres y desembarazadas para que los nuevos arrendatarios entrasen a barbechar ${ }^{51}$. En las dehesas a pasto y labor las condiciones solían ser más estrictas y sólo se permitía el cultivo en zonas limitadas durante los primeros seis años ${ }^{52}$.

En Toledo, el arrendamiento a corto plazo parece más relevante que en otras grandes instituciones eclesiásticas castellanas ${ }^{53}$. La segunda mitad del siglo xvi fue la época de expansión de esta fórmula contractual. Entre la quinta y la última década del siglo el número de contratos a corto se duplicó. En la primera parte del siglo XVII también hubo crecimiento, a pesar del descenso de los años treinta. El máximo de todo el periodo se alcanzaría en el decenio 1641-1650.

50. La duración efectiva media de este tipo de contrato fue de 8,2 años. Hay otras fórmulas minoritarias con plazos más breves: 33 contratos fueron suscritos por ocho años; 2 por siete años; 29 por seis años; 3 por cuatro años; 2 por tres años; 1 por dos años; y 4 por un año.

51. Así sucede, por ejemplo, en los heredamientos de Albalá. ABCT, Obra y Fábrica, Protocolos.

52. Caso, por ejemplo, de Benquerencia o Canillas. ABCT, Obra y Fábrica, Protocolos.

53. En Sevilla, alrededor del $10 \%$ de los contratos de arrendamiento eran cesiones a corto plazo entre los siglos XVI y XVII (GONZÁLEZ MARISCAL, 2013: 290). 


\section{GRÁFICO 1}

\section{Contratos suscritos por el cabildo de la catedral de Toledo, 1521-1650 (por decenios)}

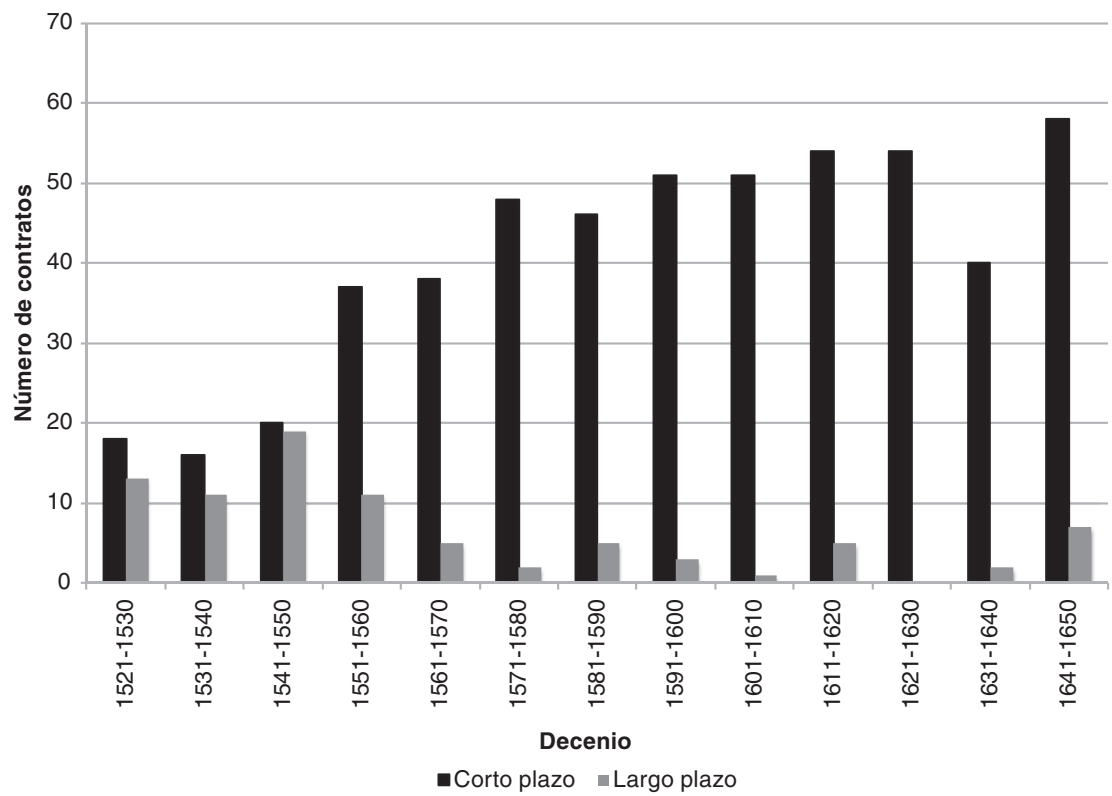

Fuente: ABCT, Obra y Fábrica, Protocolos, Posesiones y Carta Cuenta.

\section{GESTIÓN DE LAS PROPIEDADES RÚSTICAS}

Aunque los protocolos tienden a reflejar la catedral toledana como un propietario absentista, no parece que esta fuese muy ajena a la gestión de sus posesiones (González Agudo, 2017). Los canónigos tenían, a través de los diezmos, conocimiento detallado sobre la capacidad productiva de las tierras. También estaban informados sobre los mercados de factores y productos donde se ubicaban las propiedades. Su poder de negociación y su influencia local les permitieron minimizar costes de supervisión y sancionar a los usufructuarios incumplidores ${ }^{54}$.

54. Buen ejemplo son las penalizaciones por incumplimientos sobre el cultivo o mantenimiento de la explotación, reflejadas en un pago adicional a la renta del año. Algunas cláusulas particulares establecían, por ejemplo, la prohibición de sembrar grano en las huertas y en las dehesas, a no ser que las últimas fuesen a pasto y labor. En ese caso, se fijaban ciertas limitaciones, como restringir el área de siembra y el tiempo de cultivo. Es el caso de la dehesa de Canillas. ABCT, Obra y Fábrica, Protocolos, 1.131, fol. 350 . 


\section{GRÁFICO 2}

Deudas y retrasos, 1520-1610. Porcentaje sobre la renta de la muestra (dinero + gallinas) en maravedíes corrientes

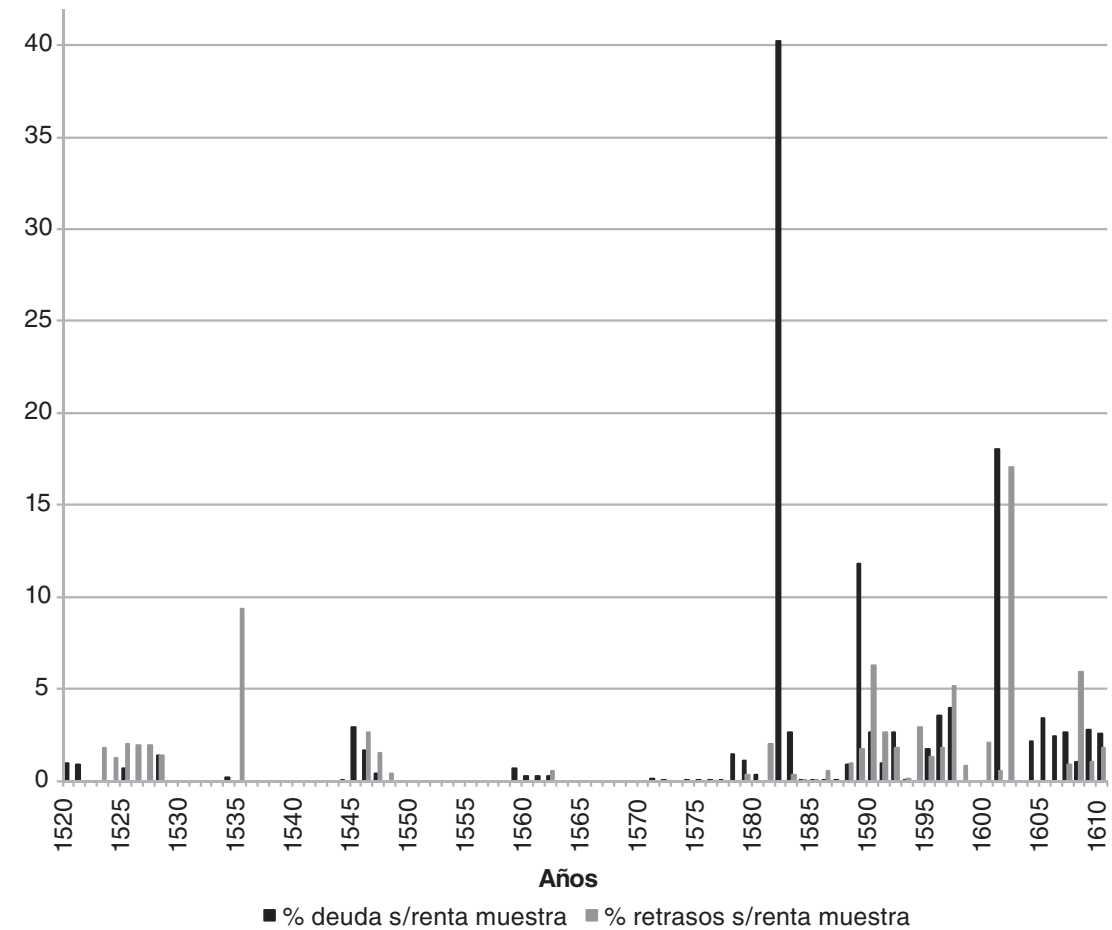

Fuente: ABCT, Obra y Fábrica, Carta Cuenta.

El Gráfico 2 ilustra cierta tolerancia hacia deudas y atrasos en el pago de la renta en coyunturas depresivas, para evitar el abandono de las tierras. El cabildo concedía esperas a ciertos arrendatarios ${ }^{55}$ y toleró deudas que, en 1582, alcanzarían el $40 \%$ de los ingresos totales de la muestra. Esto pudo tener relación con varias catástrofes meteorológicas que derivaron en pestilencias y en una crisis de subsistencias $(1578-1581)^{56}$. Deudas y rezagos serían más frecuentes a finales del siglo y comienzos del siguiente, coincidiendo con un descenso del producto agrario en la región ${ }^{57}$. También se aprecian rebajas discrecio-

55. Por ejemplo, en 1546 el cabildo ordenó a Vasco Vázquez esperar al año siguiente en el pago del arrendamiento de la dehesa de Valdemozárabes. ABCT, Obra y Fábrica, Carta Cuenta.

56. Durante 1582 se acumularon deudas en los heredamientos de Alcardete, Ajofrín, Santa Olalla, Maqueda, en el señorío de Azaña y en las dehesas de Benquerencia, Mazaraveda y Mazarracín. ABCT, Obra y Fábrica, Carta Cuenta. Sobre las crisis de subsistencias y catástrofes naturales que afectaron a Toledo, véanse MARTZ (1983: 93-100) y CARROBLES et al. (2014: 320-325).

57. Así se refiere en Sebastín Amarilla et al. (2008) sobre las fuentes diezmales del arzobispado. 
nales de la renta en algunas posesiones ${ }^{58}$ y un interés en no renovar antiguos contratos ante coyunturas favorables ${ }^{59}$.

Los arrendamientos solían ser adjudicados en subastas o remates públicos. Las tierras vacantes se publicitaban con uno o dos años de antelación mediante cédulas y pregones en la ciudad y en pueblos cercanos a la posesión. El día del remate se repetía el pregón en el cabildo y varios postores acudían a las pujas. Una vez rematadas, se obligaba a los adjudicatarios a dar fianzas ${ }^{60}$. Este procedimiento, vinculado en buena medida a la evolución del medio agrario toledano, fue seguido por otras grandes instituciones religiosas de la ciudad ${ }^{61}$.

\section{USUFRUCTUARIOS}

¿Cómo fue el contexto social del mercado de la tierra en el Toledo moderno? ¿Quién arrendaba o acensuaba las tierras de la catedral? La carta cuenta consigna datos sobre la identidad y ocupación de los usufructuarios. En la muestra, los oficios se citan en 1.929 pares propiedad-año, algo menos de un tercio (29\%) del total de entradas ${ }^{62}$; un porcentaje relativamente bajo ${ }^{63}$.

Un cambio en la documentación impide conocer deudas y rezagos desde la segunda década del siglo XVII.

58. Las quitas se produjeron en Higueruela (1545), mediante una concordia con el cabildo; en la huerta de Alaytique (1554-1561), por los daños que causó el desbordamiento del río Tajo; en las Olivas de Portillo (1557), por ser muy pobre su arrendatario; en Higueruela y Hovaniel (1559) porque se cobró de más a su tenedor, el canónigo Francisco Fernández; en la dehesa de Canillas (1582), por no estar barbechada la parte de labor al comienzo del nuevo arrendamiento; y en la dehesa de Valdemozárabes (1596-1602) porque se ordenó bajar la renta por acto capitular.

59. En 1578 moría Juan de Santa Clara, arrendatario ad vitam del heredamiento de Fuente Altamia. El cabildo reclamó el importe de la puja del nuevo arrendamiento, dado que sus herederos pretendían continuar por la tácita el antiguo. ABCT, Obra y Fábrica, Carta Cuenta.

60. ABCT, Obra y Fábrica, Oficios y Cargos, 909, fols. 12-14. «Relación de la orden que se tiene en rematar las posesiones del refitor».

61. Los remates públicos fueron habituales en los arrendamientos del Toledo moderno. El mismo procedimiento fue utilizado por el monasterio de Santo Domingo el Real, otro gran propietario de posesiones rústicas y urbanas de la ciudad (BARRIOS, 1997: 89-90). Sobre los remates de posesiones urbanas del cabildo toledano, véase Drelichmany GonZÁlez Agudo (2014: 7).

62. En aquellos arrendamientos donde el oficio del tomador se cita en una sola ocasión, he imputado ese mismo oficio para el resto de los años del contrato.

63. En una muestra de 183 posesiones urbanas del cabildo entre 1489 y 1650 , las ocupaciones de los usufructuarios se consignan en el $60 \%$ de los pares propiedad-año (DrELICHMAN \& GonZÁLEZ Agudo, 2014: 9). 
Entre 1521 y 1650 se describen cuarenta oficios diferentes, agrupados en once categorías (Cuadro 2). Clérigos y élites locales asumieron dos tercios $(66,8 \%)$ de los contratos que citan la ocupación del usufructuario. La mitad de ellos son canónigos o eclesiásticos vinculados a la catedral, quienes pudieron contar con mejor acceso al mercado de tierras. Algo parecido debió suceder con clérigos de menor rango. Esta categoría engloba, principalmente, a eclesiásticos residentes en pueblos y lugares próximos a las posesiones ${ }^{64}$.

\section{CUADRO 2}

Categorías socioprofesionales de los usufructuarios

de las propiedades de la muestra, 1520-1650

\begin{tabular}{|c|c|c|c|}
\hline Categoría laboral & Descripción & $\begin{array}{c}\text { Número } \\
\text { observaciones }\end{array}$ & $\begin{array}{c}\% \\
\text { observaciones }\end{array}$ \\
\hline \multirow[t]{2}{*}{ 1. Artesanos } & Oficios definidos por su gremio. & & \\
\hline & Requerían un periodo de aprendizaje y cierta inversión de capital. & 137 & 7,1 \\
\hline 2. Tenderos & Vendedores minoristas, en general, de productos de abasto. & 48 & 2,5 \\
\hline \multirow[t]{2}{*}{ 3. Mercaderes } & Personas dedicadas al comercio de larga distancia o intensivo & & \\
\hline & en capital. Incluye banqueros y cambistas. & 89 & 4,6 \\
\hline 4. Clérigos (bajo rango) & Eclesiásticos de bajo rango o no vinculados a la catedral. & 246 & 12,8 \\
\hline \multirow[t]{2}{*}{ 5. Clérigos (alto rango) } & Eclesiásticos de alto rango, incluyendo canónigos o cargos & & \\
\hline & de responsabilidad en la catedral. & 652 & 33,8 \\
\hline 6. Agricultores & Labradores y hortelanos. & 249 & 12,9 \\
\hline \multirow[t]{2}{*}{ 7. Servicios (alto rango) } & $\begin{array}{l}\text { Personal de servicios de alto rango y cualificación, } \\
\text { incluyendo sirvientes de nobles y canónigos, y algunos cargos }\end{array}$ & & \\
\hline & administrativos no eclesiásticos de la catedral. & 43 & 2,2 \\
\hline 8. Notarios & Notarios legos y eclesiásticos. & 37 & 1,9 \\
\hline 9. Médicos & Médicos, físicos, cirujanos o boticarios. & 16 & 0,8 \\
\hline 10. Élites locales & Altos cargos de la administración civil, militar y beneficencia. & 390 & 20,2 \\
\hline 11. Construcción & Albañiles y otros dedicados a la construcción. & 22 & 1,1 \\
\hline Total & & 1.929 & 100,0 \\
\hline
\end{tabular}

Fuente: ABCT, Obra y Fábrica, Carta Cuenta, Posesiones y Protocolos.

Las élites locales siguen a los clérigos en importancia, con un 20,2\% del total de observaciones. Aquí pueden encontrarse regidores, jurados, fiscales, procuradores, comendadores, alcaides, capitanes, caballeros, fieles de la renta del vino y contadores. Es probable que buena parte de estos usufructuarios no explotase directamente las posesiones, no descartándose el subarriendo ${ }^{65}$.

64. También aparece algún cargo dependiente del tribunal de la Inquisición, como el de receptor del Santo Oficio.

65. No he hallado prohibiciones expresas de subarrendar las posesiones. Tampoco encuentro refe- 
El nivel de endogamia fue bastante alto en los cabildos españoles modernos, donde primaban relaciones familiares y clientelares. El vínculo del alto clero con los notables locales es un hecho demostrado ${ }^{66}$. La Iglesia era lugar preferente para situar a los segundogénitos de las clases privilegiadas. Sánchez González (2000) ofrece indicios de relación entre los canónigos y las élites dirigentes toledanas. Los protocolos notariales de los primeros ofrecen una aproximación a sus ingresos: aparte de los derivados de la actividad capitular, también procedían de subarriendos de posesiones urbanas y rurales, censos, transacciones inmobiliarias o de la venta de granos.

Las entradas que no consignan oficio pueden aludir a tenedores más humildes: labradores y hortelanos cuya ocupación no se consideraba notoria en los registros del refitor. Puede ser el caso de vecinos rurales que, mancomunados o no, asumieron las tierras para explotarlas directamente. Ello puede explicar la baja representatividad de esta categoría, con un $12,9 \%$ de las observaciones ${ }^{67}$.

El resto de las categorías es minoritario ( $20 \%$ del total) y corresponde a oficios civiles urbanos: artesanos, mercaderes, tenderos, personal de servicios de alto rango, notarios, trabajadores de la construcción y médicos. No se han encontrado usufructuarios de baja cualificación, como jornaleros o trabajadores.

El Cuadro 3 ofrece, en varios cortes temporales, una evolución del comportamiento de los usufructuarios de la muestra, según su categoría socioprofesional conocida. A mediados del siglo Xvi los privilegiados llegaron a copar el 35\% de las posesiones de la muestra. Después se aprecia un descenso que tocará fondo en torno a 1600 , con un $13 \%$, seguido de una paulatina recuperación en la primera mitad del seiscientos. Entretanto, los no privilegiados perdieron terreno durante la edad de oro de la ciudad, y se quedaron sin contratar propiedades a finales del siglo XVI. A continuación se produjo una recuperación que les llevaría a tener, hacia 1625, un $11 \%$ de las posesiones. Finalmente, a mediados del siglo XVII la representatividad de los privilegiados había aumentado en detrimento de

rencias que aludan a supuestos subarriendos de las propiedades rústicas; una documentación que, de existir, sería ajena a los fondos del refitor.

66. En Jaén, casi tres cuartos de los prebendados eran de origen nobiliario; en Córdoba, la proporción superaba el $80 \%$, primando la baja nobleza; en Granada el cabildo estaba integrado por personas procedentes de familias hidalgas y de funcionarios; en Tarragona los prebendados solían proceder de casas acomodadas, campesinos propietarios, comerciantes, abogados, artesanos y nobleza; en Barcelona, más de la mitad de los capitulares conocidos eran nobles; en Murcia también predominaron los hidalgos (MORGADO, 2006: 81).

67. Un indicio a favor de este hecho podría encontrarse en el estudio de DRELICHMANy GoNZÁLEZ AGUDO (2014) sobre las propiedades urbanas del cabildo, donde se consigna un porcentaje más alto de oficios a los usufructuarios de los barrios ricos de la ciudad que a los de los pobres. 
la de los menos pudientes. Con todo, estas evidencias no son suficientes para confirmar tales movimientos en el mercado toledano de tierras.

\section{CUADRO 3}

Promedio de posesiones rurales arrendadas o acensuadas por clases privilegiadas y no privilegiadas de Toledo y porcentajes sobre el total de la muestra en varios cortes temporales, $1520-1650$

\begin{tabular}{|c|c|c|c|c|c|c|c|c|}
\hline \multicolumn{9}{|c|}{ Posesiones arrendadas/acensuadas por clases privilegiadas } \\
\hline Periodo & Clero É & Elites urbanas & s Servicios alto rango $\mathrm{N}$ & Notarios & \multirow{2}{*}{\multicolumn{2}{|c|}{$\begin{array}{c}\text { Mercaderes } \\
1,3\end{array}$}} & Suma & $\%$ total \\
\hline 1520-1522 & 6,3 & 2,0 & 0,3 & 1,7 & & & 11,7 & 23,3 \\
\hline 1549-1551 & 11,3 & 4,7 & 0,7 & 1,0 & \multicolumn{2}{|c|}{0,0} & 17,7 & 35,3 \\
\hline 1574-1576 & 8,0 & 1,0 & 0,7 & 0,0 & \multicolumn{2}{|c|}{2,7} & 12,3 & 24,7 \\
\hline 1599-1601 & 3,0 & 2,3 & 0,0 & 0,0 & \multicolumn{2}{|c|}{1,3} & 6,7 & 13,3 \\
\hline 1624-1626 & 5,7 & 0,7 & 0,3 & 0,0 & \multicolumn{2}{|c|}{1,0} & 7,7 & 15,3 \\
\hline $1648-1650$ & 7,3 & 2,0 & 0,0 & 0,0 & \multicolumn{2}{|l|}{0,0} & 9,3 & 18,7 \\
\hline \multicolumn{9}{|c|}{ Posesiones arrendadas/acensuadas por clases no privilegiadas } \\
\hline Periodo $A$ & Artesanos & s Tenderos & Agricultores y albañiles & \multicolumn{2}{|c|}{ Boticarios } & \multicolumn{2}{|c|}{ Suma } & $\%$ total \\
\hline 1520-1522 & 1,7 & 1,0 & 1,7 & \multicolumn{2}{|r|}{0,3} & 4,7 & & 9,3 \\
\hline 1549-1551 & 0,3 & 0,0 & 0,3 & \multicolumn{2}{|r|}{0,0} & 0,7 & & 1,3 \\
\hline 1574-1576 & 1,3 & 0,0 & 1,0 & \multicolumn{2}{|r|}{0,0} & 2,3 & & 4,7 \\
\hline 1599-1601 & 0,0 & 0,0 & 0,0 & \multicolumn{2}{|r|}{0,0} & 0,0 & & 0,0 \\
\hline $1624-1626$ & 0,0 & 0,3 & 5,3 & \multicolumn{2}{|r|}{0,0} & 5,7 & & 11,3 \\
\hline $1648-1650$ & 0,0 & 0,0 & 2,0 & \multicolumn{2}{|r|}{0,0} & 2,0 & & 4,0 \\
\hline
\end{tabular}

Fuente: ABCT, Obra y Fábrica, Carta Cuenta, Posesiones y Protocolos.

Los aspectos hasta aquí descritos permiten plantear una cuestión interesante. ¿Eran las rentas capitulares toledanas un fiel reflejo del mercado de tierras? Por una parte, es posible que su funcionamiento fuese alterado por intereses personales o familiares entre canónigos y usufructuarios. A la par, el subarriendo es algo más que una posibilidad entre las cesiones a los privilegiados ${ }^{68}$. Por otra parte, que las posesiones capitulares se adjudicaran al mejor postor y que este asumiera posibles riesgos pagando un precio más alto sí parece expresar una voluntad de maximizar utilidad e ingresos por parte de los agentes económicos. La intermediación de eclesiásticos y parientes podría ser, también, un medio de minimizar costes de gestión o de asegurar el pago de la renta en épocas de incer-

68. SÁNCHEZ GoNZÁLEZ (2000: 31-45), que indagó en una treintena de protocolos notariales de canónigos toledanos, apunta que parte de sus ingresos procedían de arrendamientos de tierras e inmuebles urbanos. Un estudio más detallado de los protocolos permitirá averiguar si entre estas propiedades se hallaban posesiones capitulares previamente adjudicadas a los canónigos. 
tidumbre. En cualquier caso, hasta que estas cuestiones no queden debidamente resueltas con la documentación notarial, habrá que tomar con bastantes reservas el análisis coyuntural de la renta que se ofrece a continuación.

\section{TRAYECTORIA DE LA RENTA DE LA TIERRA}

El Gráfico 3 muestra la trayectoria, a precios constantes, de la renta de la tierra total, de las dehesas y de las tierras de labor de la muestra capitular. Como deflactores se han utilizado el índice de precios de Toledo (IPT) y un índice de precios de productos agrarios (IPA) ${ }^{69}$.

Tomando como deflactor el IPT, se aprecian dos trayectorias claramente divergentes: la renta de las labranzas tuvo un crecimiento modesto (30\%) entre $1521-1529$ y $1642-$ 1650 , mientras que la de las dehesas descendió un $57 \%$. La discordancia entre ambas se aprecia a partir de la década de 1570. La renta de los labrantíos siguió creciendo hasta aproximadamente 1584, para después caer hasta la entrada del siglo XVII. En cambio, la renta de las dehesas descendió hasta el final del periodo. Con el deflactor del IPA, las tendencias generales en labrantíos y dehesas fueron muy parecidas a las seguidas utilizando el IPT. Entre 1521-1529 y 1642-1650 la renta de las labranzas creció un 28\% y la de las dehesas descendió un $57,5 \%$.

Varios factores podrían explicar, al menos en parte, esta divergencia. Uno es el crecimiento urbano del siglo XvI, que pudo incrementar la demanda de productos agrícolas y, por consiguiente, de tierras cultivables ${ }^{70}$. Una parte importante de los labrantíos de la muestra estaba en La Sagra y Torrijos, comarcas situadas entre Madrid y Toledo. En esta ciudad, las reservas del granero municipal se multiplicaron por 3,75 entre 1563 y 1582.

69. Sobre el IPT, véase GonZÁlEz Agudo (2017). Para el índice de precios agrarios, he elegido las series de precios más consistentes de los principales productos de las posesiones de la muestra: cereales (trigo), carnes (carnero), vino y aceite. Al asignar las ponderaciones, he considerado la superficie que representaban los diferentes usos de la tierra en la muestra. La alta representatividad de los pastos implicaría una ponderación relativamente alta para los precios de la carne. No obstante, la dedicación a pasto y labor de muchas dehesas implicaría que el área dedicada a pasturas pudo ser, en realidad, menor. De este modo, para el IPA he decidido asignar un peso específico del $60 \%$ al precio del trigo, un $25 \%$ al precio del carnero, un $10 \%$ al precio del vino y un $5 \%$ al del aceite de oliva.

70. Según los censos, Toledo duplicó su población entre 1528-1530 y 1571 (MARTZ, 1983: 93). Madrid alcanzaría una cifra máxima de población (83.000 almas) hacia 1600 (AlvAR, 1989: 33). En apenas cuatro décadas la población madrileña se multiplicó por 4,5, y llegó a convertirse en una de las urbes más populosas de Europa. Las necesidades urbanas de cereal pasaron, aproximadamente, de 700 a 1.100 fanegas diarias entre 1584 y 1600 (LóPEZ GARCÍA, 1998: 77, 103). Sobre la trayectoria demográfica madrileña durante el reinado de Felipe II, véase también CARBAJO (1987: 132-140). 
Montemayor asocia este hecho al crecimiento urbano y ofrece mapas sobre la procedencia de las compras de cereal ${ }^{71}$. En Madrid, Bernardos señala compras directas del pósito a grandes perceptores, siendo uno de ellos, en 1577 y 1580, el cabildo de la catedral toledana $^{72}$. Asimismo, Alfredo Alvar indica que desde 1580 hasta mediados del siglo XvII se aprecia una entrada mayor de granos del sur de Madrid. En varias fechas aparecen partidas procedentes de La Sagra (1582, 1594 y 1599) y entornos de Toledo (1592 y 1599) ${ }^{73}$.

\section{GRÁFICO 3}

\section{Rentas de dehesas y de labrantíos del cabildo catedralicio de Toledo en maravedíes} constantes por hectárea, 1521-1650 (números índices, base $100=$ 1521-1529.

\section{Medias móviles de 9 años)}

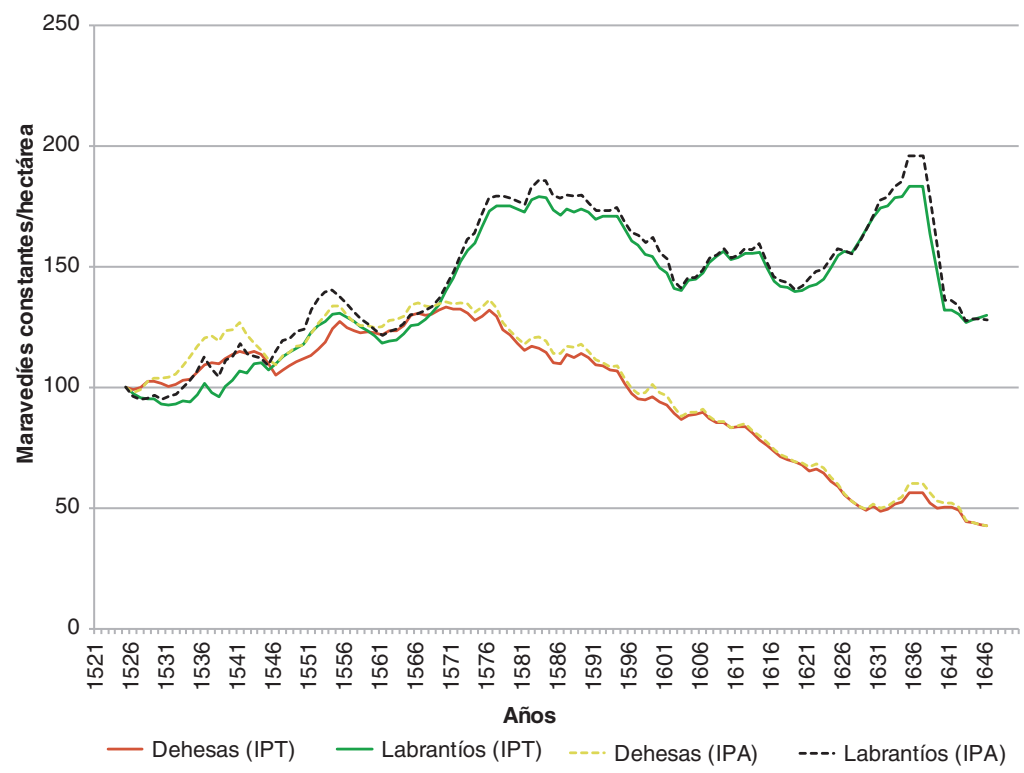

Leyenda: IPT=renta deflactada por el índice del coste de la vida en Toledo, 1521-1650; IPA=renta deflactada por el índice de productos agrarios de Toledo, 1521-1650.

Fuentes: ABCT, Obra y Fábrica, Carta Cuenta, 1.194-1.234 y libros de los años 1600-1650.

Otros factores que podrían explicar la divergencia entre labrantíos y dehesas son el aumento de los derechos de exportación, la evolución desfavorable de la demanda exterior de lana y las fuertes alzas impositivas sobre las ciudades castellanas. Los dos primeros de-

71. Ya en 1561-1562, el grueso de las compras de cereal aparece repartido en las comarcas de La Sagra y Torrijos, incluso en lugares donde se hallaban labrantíos del cabildo catedralicio como Azaña, Cobeja, Portillo o Yuncler (MONTEMAYOR, 1996: 70, 88).

72. Bernardos (1997: 79).

73. Alvar (1989: 110-111). 
bieron perjudicar a las exportaciones de vellones, a la cría de ganado lanar y, por consiguiente, a la renta real de los arrendamientos en las dehesas ovejunas (Llopis, 1991). La guerra de los Países Bajos de 1568 pudo, además, acentuar la decadencia de las exportaciones hacia Flandes, un declive que se había iniciado a mediados de la centuria (Casado, 1994). En cuanto a las alzas tributarias, Toledo y su tierra soportaron en 1575 la triplicación de la tasa de alcabalas (Martz, 1983: 97), que fueron especialmente gravosas sobre los productos de origen ganadero ${ }^{74}$.

En la primera mitad del siglo XVII la tendencia general de la renta de los sembradíos de la muestra fue descendente. A corto plazo se aprecian altibajos que pudieron guardar relación con los vaivenes de la coyuntura agraria en la región y con la evolución de la demanda urbana de grano en Toledo y Madrid (González Agudo, 2017). Por su parte, la caída de la renta de las dehesas fue más pronunciada. Esta desvalorización pudo ser causada por la crisis ganadera y por el fuerte declive demográfico de Toledo ${ }^{75}$. En esta época, las guerras y las transformaciones textiles europeas contribuyeron a deprimir la demanda de lana fina, a la que la industria pañera del interior no pudo hacer frente. La situación afectaría negativamente a las explotaciones ganaderas y, por ende, a los usufructuarios de las dehesas catedralicias ${ }^{76}$. Algunos autores argumentan mayores descensos de la renta en este tipo de explotaciones, por ser más susceptibles de quedar vacantes si el propietario se resistía a rebajar el precio ante coyunturas adversas (ÁlvarezVázquez, 1987: 51). Esto último es lo que, efectivamente, acabaría sucediendo en siete dehesas capitulares $^{77}$.

Por último, otra posible causa del descenso de las rentas de pastizales pudo ser la reducción del área cultivada en las dehesas de pasto y labor. El rompimiento de tierras de pasto estuvo muy extendido durante el siglo XvI, al compás del incremento demográfico (Marcos, 2000: 360-361). Cabe pensar que el aumento de la renta de las dehesas en la

74. Tomando como base 100 los años 1557-1561, la ciudad de Toledo fue una de las que sufrió un mayor incremento del encabezamiento de alcabalas en Castilla, que llegó a alcanzar un índice 411 en 1579-1584. En el mismo periodo, la alcabala alcanzó los siguientes índices en diferentes gremios: 1.455 en tratos de lienzos y sayales; 925 en zapatería; 828 en aceite, queso y miel; 809 en paños de oro y seda; y 579 en paños de color-tapetes (ZABALA, 2000).

75. Los registros bautismales en trece parroquias de Toledo muestran una caída del $30 \%$ entre 1590 y 1607, y un descenso muy profundo entre 1605 y 1636 (MARTZ, 1983).

76. Entre las transformaciones textiles de la época se halla el derrumbe de la pañería de lujo y el tránsito, en los países europeos del norte, a la denominada new draperie, que requería menor calidad de las lanas (MARCos, 2000: 498).

77. Quedaron vacantes Canillas (1600), Darageval (1618-1621), Mazaraveda (1624), Valdecubas (1634-1642), Regachuelo de Canales (1635-1641 y 1646-1648), Alpuébrega (1647) y Villeriche (1647-1649). 
primera mitad del siglo XvI había dependido tanto de su parte de pastizal como del creciente valor de las partes roturadas. Al cambiar la coyuntura a finales de siglo, los rompimientos decayeron con la demanda de pan que los había originado. Al ser terrenos de calidad inferior a los labrantíos frecuentes, la superficie cultivada en las dehesas toledanas pudo reducirse, pese al hecho diferencial de la demanda madrileña. Al ser tan notable la presencia de dehesas de pasto y labor en la muestra, la porción roturada de ellas, por pequeña que fuese, hubo de ser de cierta consideración ${ }^{78}$. El problema está en que los documentos no permiten conocer la superficie labrada en las citadas dehesas.

En suma, es probable que un creciente diferencial de rentabilidad a favor del cultivo, vinculado al crecimiento demográfico, se uniese a una elevación de los costes de las actividades ganaderas en los contornos de Toledo, hasta el punto de mermar la demanda de espacios de pasto y desinflar el nivel de sus rentas. Las fuentes permiten comprobar que el cabildo catedralicio no fue ajeno a la situación. Los canónigos intentaron evitar las pérdidas de rentabilidad fragmentando sus dehesas más extensas y cediéndolas en partes más reducidas ${ }^{79}$. Sin embargo, las vacantes producidas en algunas de estas posesiones durante la primera mitad del siglo XVII indican que las divisiones no tendrían el éxito esperado.

\section{CONCLUSIONES}

Entre 1521 y 1650, las rentas rústicas de una muestra representativa de propiedades de la catedral de Toledo supusieron entre un $16 \%$ y un $34 \%$ del total de los ingresos. Conviene señalar que la imposibilidad de distinguir entre rentas territoriales y señoriales en varias posesiones impide conocer, exactamente, la cantidad percibida por rentas de la tierra.

Los canónigos toledanos cobraron las rentas en dinero y en gallinas, si bien predominó el monto en metálico. Esta preferencia se explicaría por la huida de los elevados costes de recogida y comercialización del grano recaudado; por cierta cautela en la inmunidad eclesiástica sobre la libre circulación y venta de granos, para evitar posibles fricciones con las élites civiles; y por un considerable desarrollo comercial y mercantil de la ciudad. No

78. Las dehesas suponen 13.414 hectáreas de un total de 15.407 en la muestra. Si suponemos, por ejemplo, que las porciones roturadas afectaron al $15 \%$ de la superficie en el momento álgido de su expansión en el siglo XVI, serían 2.010 hectáreas, una extensión algo mayor que la de los labrantíos (1.993 hectáreas).

79. De ello dan buena cuenta las divisiones producidas en las dehesas de Benquerencia y Canillas (1563), Algurilla y Mazaraveda (1598), Valdecubas (1616), Montalbanejos (1619) y Darageval (1621). 
obstante, la cobranza de parte de la renta en gallinas pudo suponer una salvaguardia contra la inflación y las manipulaciones monetarias.

Resulta llamativa la concentración de propiedades capitulares, el predominio de las grandes superficies y la importancia de las dehesas. Estos terrenos, dedicados principalmente a pasto y labor, suponen más del $80 \%$ de la extensión muestral, si bien contienen una porción de tierra labrantía, cuyas rentas son desconocidas.

El censo, vinculado a labranzas relativamente pequeñas, fue el contrato mayoritario entre las posesiones catedralicias. El importe de los censos no se actualizaba y su valor real se veía afectado por la inflación. Esto explica su reducido porcentaje sobre el total de las rentas territoriales. Los arrendamientos eran, en cambio, los que más ingresos aportaban. En esta clase de cesiones los contratos a corto plazo fueron mayoritarios, destacando los de nueve años. La segunda mitad del siglo Xvi fue la época de expansión de esta fórmula, cuyas renovaciones permitían actualizar la renta.

La muestra parece reflejar una clara divergencia entre las trayectorias de las rentas en las labranzas «puras» y en las dehesas: entre 1521-1529 y 1642-1650 las primeras aumentaron $(28 \%)$ y las segundas cayeron $(-57 \%)$. La rentabilidad creciente del cultivo y la elevación de costes de las actividades ganaderas pudieron aumentar las rentas de los labrantíos y desinflar las de los pastizales desde la década de 1570. Los canónigos intentarían, no siempre con éxito, evitar las posibles pérdidas fragmentando sus dehesas más extensas y cediéndolas en partes más pequeñas. Por último, el balance general desde los años ochenta hasta el final del periodo de estudio fue negativo, a pesar del mejor comportamiento de la renta labrantía. Entonces, la coyuntura depresiva de la región y la progresiva reorientación del abasto madrileño de granos, pan y harinas pudieron afectar a las labranzas capitulares, relativamente próximas a la nueva sede de la monarquía castellana.

De momento, asuntos de mayor calado obligan a considerar como provisional el análisis clásico de la renta de la tierra. Por un lado, resulta llamativo que canónigos y élites locales asumieran dos tercios de los arrendamientos donde se conoce la ocupación del usufructuario. ¿Cómo influyó ese vínculo entre privilegiados en el mercado capitular de tierras? Por otro lado, parece que tanto la catedral toledana como los adjudicatarios de las tierras se comportaron como agentes económicos que, al asumir riesgos, procuraron maximizar sus ingresos y utilidad. ¿Prevalecieron aquí los intereses corporativos o el ideal de maximización de la renta? Estas cuestiones se abordarán en trabajos futuros, a través del manejo de protocolos notariales. 


\section{AGRADECIMIENTOS}

Agradezco las consideraciones de los revisores de Historia Agraria, la asistencia de Eva Fernández, así como también los sabios comentarios de José Antonio Sebastián Amari1la, Enrique Llopis Agelán, Pegerto Saavedra, María Seixas y demás participantes en la sesión sobre patrimonios eclesiásticos del Congreso de Historia Agraria SEHA-RURALREPORT (Santiago de Compostela, 2018).

\section{REFERENCIAS}

Aguadé, S. (1982). Política arrendataria del monasterio de Villanueva de Oscos (s. XIII): Evolución de la renta de la tierra en Asturias durante el siglo XIII. En Semana de historia del monacato cántabro-astur-leonés (pp. 235-270). Oviedo: Monasterio de San Pelayo.

Allen, R. C. (1988). The Price of Freehold Land and the Interest Rate in the Seventeenth and Eighteenth Centuries. The Economic History Review, 41 (1), 33-50.

Alvar, A. (1989). El nacimiento de una capital europea: Madrid entre 1561 y 1606. Madrid: Turner Libros/Ayuntamiento de Madrid.

Álvarez VÁzquez, J. A. (1987). Rentas, precios y crédito en Zamora en el Antiguo Régimen. Zamora: Colegio Universitario de Zamora.

Amalric, J. P. (1985). Une exploitation avortée: La labranza de Villanubla (Valladolid). En J. P. AmAlRIC \& P. Ponsot (Dirs.), L'exploitation des grands domaines dans l'Espagne d'Ancien Régime (pp. 223-248). Paris: Éditions du CNRS.

ANEs, G. (1970). Las crisis agrarias en la España moderna. Madrid: Taurus.

ARDIT, M. (2006). La evolución de la renta feudal en el marquesado de Llombai (siglos XVI-XIX). Revista de Historia Moderna:Anales de la Universidad de Alicante, (24), 1130.

BARRIOS, J. L. (1997). Arrendamientos y subarrendamientos de inmuebles urbanos en Toledo durante el siglo Xv. Anales toledanos, (34), 89-102.

Bernardos, J. U. (1997). No sólo de pan: Ganadería, abastecimiento y consumo de carne en Madrid (1450-1805). Tesis doctoral. Madrid: Universidad Autónoma de Madrid. Blázquez Garbajosa, A. (1988). El senorio episcopal de Siguenza: Economía y sociedad, 1123-1805. Guadalajara: Institucion Provincial de Cultura "Marques de Santillana». BRACHT, J. (2011). Land Rental Values as an Indicator for Long-Term Agricultural Productivity, Westphalia, 1600-1900. En Agricliometrics Conference: Zaragoza, Fune $2^{\text {nd }}$ $4^{\text {th }}$.

Brenner, R. (1976). Agrarian Class Structure and Economic Development in Pre-Industrial Europe. Past \& Present, (70), 30-75. 
Brenner, R. (1982). The Agrarian Roots of European Capitalism. Past E Present, (97), 16-113.

BRENNER, R. (1997). Property Relations and the Growth of Agricultural Productivity in Late Medieval and Early Modern Europe. En A. BHADURI \& R. SKARSTEIN (Eds.), Economic Development and Agricultural Productivity (pp. 9-41). Cheltenham: E. Elgar.

Brumont, F. (1984). Campo y campesinos de Castilla la Vieja en tiempos de Felipe II. Madrid: Siglo XXI.

Cancila, O. (1978). Sulla rendita fondiaria in Sicilia dalla fine del Quattrocento all'Unità d'Italia. En J. Goy \& E. LE Roy LADURIE (Coords.), Prestations paysannes, dîmes, rente foncière et mouvement de la production agricole à l'époque préindustrielle (pp. 174195). Paris: Éditions de l'École des Hautes Études en Sciences Sociales.

CARBajo, M. F. (1987). La población de la villa de Madrid: Desde finales del siglo XVI hasta mediados del siglo XIX. Madrid: Siglo XXI.

Carrobles, J., Barroso, R., Malalana, A., Morín de Pablos, J. \& Rodríguez MonTERO, S. (2014). Raíces medievales de los paisajes culturales de Toledo: Espacios y prácticas ganaderas en el área de cigarrales. En J. CARRoBles \& J. MoRín DE PABLOS (Eds.), Los paisajes culturales de la ciudad de Toledo: Los cigarrales: Dehesas, espacios irrigados, torres, cigarrales y trincheras (pp. 141-192). Oxford: Archaeopress.

CASAdO, H. (1994). El comercio internacional burgalés en los siglos XV y XVI. En F. BAllesteros, H. Casado, S. Escolar \& A. C. Ibáñez Pérez (Dirs.), Actas delV Centenario del Consulado de Burgos, 1494-1994 (pp. 175-247). Burgos: Diputación Provincial de Burgos.

Catalán, E. (2018). Convento pobre, convento rico: Modelos de gestión económica en los conventos de la España Atlántica. Comunicación presentada en el XVI Congreso de Historia Agraria-SEHA/VII Encontro RuralRePort. Santiago de Compostela, 2023 de junio.

Clark, G. (2002). Land Rental Values and the Agrarian Economy: England and Wales, 1500-1914. European Review of Economic History, 6 (3), 281-308.

Сово, J. (1991). Introducción. En A. MArcos, Informe de la ciudad de Toledo al Consejo de Castilla sobre igualación de pesos y medidas (pp. 7-43). Toledo: Instituto Provincial de Investigaciones y Estudios Toledanos.

Coronas, L. J. (1994). La economía agraria de las tierras de faén 1500-1650. Granada: Universidad de Granada.

Cuervo, N. (2006). La renta de la tierra y su evolución en la mitad norte de la provincia de Ávila durante los siglos XVI y XVII. Investigaciones de Historia Económica, 2 (5), 10-37.

DonÉzAr, J. M. (1984). Riqueza y propiedad en la Castilla del Antiguo Régimen: La provincia de Toledo del siglo XVIII. Madrid: Instituto de Estudios Agrarios, Pesqueros y Alimentarios. 
Drelichman, M. \& González Agudo, D. (2014). Housing and the Cost of Living in Early Modern Toledo. Explorations in Economic History, (54), 27-47.

DURÁN I PUjol, M. (1985). Consideraciones sobre el movimiento del ingreso señorial en Cataluña entre 1550 y 1800: El ejemplo del Alt Urgell. En M. GonZÁlez PorTilla, J. MALUQUER DE MOTES \& B. DE RIQUER (Eds.), Industrialización y nacionalismo: Análisis comparativos: Actas del I Coloquio Vasco-Catalán de Historia (pp. 27-44). Barcelona: Universitat Autònoma de Barcelona.

Epstein, S. R. (2000). Freedom and Growth: The Rise of States and Markets in Europe, 1300-1750. London: Routledge. (Routledge Explorations in Economic History).

Fernández Collado, A. (1999). La catedral de Toledo en el siglo XVI:Vida, arte, personas. Toledo: Diputación Provincial de Toledo.

Fernández Collado, A. (2005). Las rentas del clero en 1822: Arzobispado de Toledo. Toledo: Instituto Teológico San Ildefonso/Diputación Provincial de Toledo.

Fernández de Pinedo, E., Gil Novales, A. \& Dérozier, A. (1980). Centralismo, ilustración y agonía del Antiguo Régimen (1715-1833). En M. TUÑón DE LARA (Dir.), Historia de España. T. 7. Barcelona: Labor.

García Sanz, A. (1977). Desarrollo y crisis del Antiguo Régimen en Castilla laVieja: Economía y sociedad en tierras de Segovia, 1500-1814. Madrid: Akal.

García SANZ, A. (1985). Auge y decadencia en España en los siglos XVI y XVII: Economía y sociedad en Castilla. Revista de Historia Económica, 3 (1), 11-27.

García Sanz, A., Martín, J. L., Pascual, J. A. \& Pérez Moreda, V. (1981). Propiedades del cabildo segoviano: Sistemas de cultivo y modos de explotacion de la tierra a fines del siglo XIII. Salamanca: Universidad de Salamanca.

GonZÁLEZ AGUdo, D. (2011). Aproximación a la renta de la tierra y su evolucion en Castilla la Nueva durante el Quinientos: El cabildo catedralicio de Siguenza. Comunicación presentada en el X Congreso Internacional de la AEHE. Carmona, 8 de septiembre.

GonzÁlez Agudo, D. (2017). Población, precios y renta de la tierra en Toledo, siglos XVIXVII. Tesis doctoral. Madrid: Universidad Complutense de Madrid. http://eprints. ucm.es/40769/

González Mariscal, M. (2008). Propiedad, explotación y renta de la tierra en Sevilla, 1500-1700. Comunicación presentada al XII Congreso de Historia Agraria. Córdoba, 13-15 de marzo.

GonzÁlez Mariscal, M. (2013). Población, coste de la vida, producción agraria y renta de la tierra en Andalucía Occidental, 1521-1800. Tesis doctoral. Madrid: Universidad Complutense de Madrid. http://eprints.ucm.es/22947/1/T34764.pdf

HeRnándeZ, F. J. (1985). Los cartularios de Toledo: Catálogo documental. Madrid: Fundación Ramón Areces. 
Hoffman, P.T. (2000). Growth in a Traditional Society: The French Countryside, 14501815. Princeton: Princeton University Press.

Instituto Nacional de Estadística (INE) (1992). Censo de 1797 «Godoy». Madrid: Instituto Nacional de Estadística.

IzQuierdo, R. (1980). El patrimonio del cabildo de la Catedral de Toledo: Segunda mitad del siglo XIV. Toledo: Caja de Ahorro Provincial de Toledo.

LADERO, M. A. (1982). El siglo XV en Castilla. Fuentes de renta y política fiscal. Barcelona: Ariel.

Le Roy Ladurie, E. (1966). Les paysans de Languedoc. Paris: [s. n.].

Lop, M. J. (2002). El cabildo catedralicio de Toledo en el siglo XV:Aspectos institucionales y sociológicos. Tesis doctoral. Madrid: Universidad Complutense de Madrid. http://biblioteca.ucm.es/tesis/ghi/ucm-t25699.PDF

Lop, M. J. (2016). La catedral de Toledo en la Edad Media: Trayectoria, funcionamiento, proyección. Toledo: Instituto Teológico San Ildefonso.

López Celada, I. (1980). Evolución de las Rentas del Cabildo de la Catedral de Toledo, durante el último cuarto del Siglo XVI. Toledo: Caja de Ahorro Provincial de Toledo.

López Estudillo, A. J. (2007). El arrendamiento de latifundios a partir de frutos: Contratos y gestión patrimonial del cabildo de la catedral de Córdoba (1700-1840). En R. ROBLEDO \& S. López GARCía (Coords.), ¿Interés particular, bienestar público?: Grandes patrimonios y reformas agrarias (pp. 65-102). Zaragoza: Prensas Universitarias de Zaragoza.

López García, J. M. (Dir.) (1998). El impacto de la Corte en Castilla: Madrid y su territorio en la época moderna. Madrid: Siglo XXI de España.

LÓPEZ-SALAZAR, J. (1986). Estructuras agrarias y sociedad rural en la Mancha (ss. XVIXVII). Ciudad Real: Instituto de Estudios Manchegos.

López-Salazar, J. (1987). Mesta, pastos y conflictos en el Campo de Calatrava durante el siglo XVI. Madrid: CSIC/Centro de Estudios Históricos.

López-SALAZAR, J. \& MARTín GaLÁN, M. M. (1981). La producción cerealista en el Arzobispado de Toledo, 1463-1699. Cuadernos de historia moderna y contemporánea, (2), 21-104.

LLOPIS, E. (1991). La renta de las dehesas extremeñas en los dos últimos tercios del siglo Xvi. En A. Alegre et al., En memoria de $M^{a}$ Ángeles Gil Luezas (pp. 323-339). Madrid: Alfa Centauro.

Marcos, A. (1985). El aumento de la población. En A. García SANZ (Coord.), Historia de Castilla y Leon (pp. 40-51). Vol. 6. Valladolid: Ambito.

Marcos, A. (2000). España en los siglos XVI, XVII y XVIII: Economía y sociedad. Barcelona: Crítica.

MARTZ, L. (1983). Poverty andWelfare in Habsburg Spain: The Example of Toledo. Cambridge: Cambridge University Press. 
Montemayor, J. (1996). Tolède, entre fortune et déclin (1530-1640). Limoges: Presses Universitaires de Limoges.

Morgado, A. (2006). La Iglesia como factor de movilidad social: Las carreras eclesiásticas en el Antiguo Régimen. En F. Chacón \& N. G. Monteiro (Eds.), Poder y movilidad social: Cortesanos, religiosos y oligarquías en la Península Ibérica (siglos XV-XIX) (pp. 61-96). Madrid: Consejo Superior de Investigaciones Científicas.

Ormrod, D., Gibson, J. M. \& Lyne, O. (2011). City and Countryside Revisited: Comparative Rent Movements in London and the South-East, 1580-1914. Studies in Economics, (1117).

Pastor De Togneri, R. (1975). Del Islam al Cristianismo: En las fronteras de dos formaciones económico-sociales: Toledo, siglos XI-XIII. Barcelona: Península.

Pomeranz, K. (2008). Land Markets in Late Imperial and Republican China. Continuity and Change, 23 (1), 101-150.

Ponsot, P. (1986). Atlas de historia económica de la baja Andalucía: Siglos XVI-XIX. Granada: Editoriales Andaluzas Unidas.

Robledo, R. (1984). La renta de la tierra en Castilla la Vieja y León, 1836-1913. Madrid: Banco de España.

SAAVEDRA, P. (1990). Contribución al estudio del régimen señorial gallego. Anuario de historia del derecho español, (60), 103-184.

SAAVEDRA, P. (2018). El control de los patrimonios monásticos en la Galicia moderna. Historia Agraria, (74), 7-36.

SÁNCHEZ GonZÁlez, R. (2000). Iglesia y sociedad en la Castilla moderna: El cabildo catedralicio de la sede primada (siglo XVII). Cuenca/Toledo: Universidad de Castilla-La Mancha/Ayuntamiento de Toledo.

SÁnchez Meco, G. (1985). El Escorial y la Orden ferónima: Análisis económico-social de una comunidad religiosa. Madrid: Editorial Patrimonio Nacional.

Sebastián Amarilla, J. A. (1990). La renta de la tierra en León durante la Edad Moderna: Primeros resultados y algunas reflexiones a partir de fuentes monásticas. Revista de Historia Económica, 8 (1), 53-80.

Sebastián Amarilla, J. A. (1992). Agricultura y rentas monásticas en tierras de León: Santa María de Sandoval (1167-1835). 2 vols. Madrid: Universidad Complutense de Madrid.

Sebastián Amarilla, J. A. (1999). Del «fuero» al arrendamiento:Tenencia y explotación de la tierra en León entre la Edad Media y la Edad Moderna. Revista de Historia Económica, 17 (2), 305-341.

Sebastián Amarilla, J. A. (2005). La Edad Media (c. 1000-c. 1450): Configuracion y primer despegue de la economia europea. En F. Comín, M. Hernández BENíteZ \& E. Llopis (Eds.), Historia Economica Mundial: Siglos X-XX (pp. 15-66). Barcelona: Crítica. 
Sebastián Amarilla, J. A., García Montero, H., Zafra, J. \& Bernardos, J. U. (2008). Del crecimiento a la decepcion: La produccion agraria en Castilla La Mancha en la Edad Moderna, una primera aproximacion. Comunicación presentada al IX Congreso de la Asociación Española de Historia Económica. Murcia, 9-12 de septiembre.

Soens, T. \& Thoen, E. (2008). The Origin of Lease Holding in the Former County of Flanders $\left(13^{\text {th }}-16^{\text {th }}\right.$ Century). En B. J. P. van Bavel \& P. R. Schofield (Eds.), The Development of Leasehold in Northwestern Europe, c. 1200-1600 (pp. 31-56). Turnhout: Brepols.

SuÁrez Álvarez, M. J. (1982). La villa de Talavera y su tierra en la Edad Media, 13691504. Oviedo: Universidad de Oviedo.

Torroja, C. (1977). Catálogo del Archivo de Obra y Fábrica de la catedral de Toledo. Toledo: Instituto Provincial de Investigaciones y Estudios Toledanos, Diputación Provincial de Toledo.

VAN BAVEL, B. J. P. (2001). Land, Lease and Agriculture:The Transition of the Rural Economy in the Dutch River Area from the Fourteenth to the Sixteenth Century. Past $\mathcal{E}$ Present, 172 (1).

VAN BAVEL, B. J. P. (2008a). The Organization and Rise of Land and Lease Markets in Northwestern Europe and Italy, c. 1000-1800. Continuity and Change, 23 (1), 13-53. VAN BAVEL, B. J. P. (2008b). The Emergence and Growth of Short-Term Leasing in the Netherlands and Other Parts of Northwestern Europe (Eleventh-Seventeenth Centuries): A Chronology and a Tentative Investigation into its Causes. En B. J. P. van BAVEL \& P. R. SCHOFIELD (Eds.), The Development of Leasehold in Northwestern Europe, c. 1200-1600 (pp. 179-213). Turnhout: Brepols.

Vervaet, L. (2012). Parcels and Patiens: The Lease Policy of the Saint John's Hospital of Bruges in Late Medieval Flanders. Comunicación presentada al Annual N.W. Posthumus Conference. Amsterdam.

Vervaet, L. (2013). Every Little Bit Helps? The Leasehold of Small Parcels of Land in Late Medieval Flanders. Comunicación presentada al International Conference of the European Rural History Organisation (EURHO). Berna, 19-22 de agosto.

WästFELT, A. (2013). Leasehold in Sweden 1500-1800: The Intersection between Nordic User Rights and Property Rights Inherited from Roman Law. Comunicación presentada al International Conference of the European Rural History Organisation (EURHO). Berna, 19-22 de agosto.

YANG, H. H. (2012). The Impact of Changing Agricultural Technology on Land Tenancy in Preindustrial China: Evidence from Confucius' Manors (1759-1901). Comunicación presentada al $72^{\text {nd }}$ Annual Meeting of the Economic History Association. Vancouver, 21-23 de septiembre.

Yun, B. (1985). Producción agrícola en Tierra de Campos y Segovia: Contrastes, similitudes y problemas en torno a la agricultura castellana en los siglos XVI al XVIII. Co- 
municación presentada al III Congreso de Historia Económica. Segovia, 3-5 de octubre.

Yun, B. (2004). Marte contra Minerva: El precio del imperio español, c. 1450-1600. Barcelona: Crítica.

Zabala, P. (2000). Las Alcabalas y la Hacienda Real en Castilla: siglo XVI. Santander: Universidad de Cantabria. 


\section{ANEXO 1}

Propiedades rústicas de la muestra durante los siglos XVI y XVII, superficies, aprovechamientos y términos municipales donde se encuentran

\begin{tabular}{|c|c|c|c|}
\hline Posesión & Término municipal & Superficie(ha) & Uso de la tierra \\
\hline Alcardete & Toledo & 1,88 & Viñedo/tejar \\
\hline Alaytique & Toledo & n. d. & Huerta \\
\hline Valdecubas & Toledo & 495,90 & Pastos/cereal \\
\hline Albalá & Albarreal de Tajo & 155,50 & Cereal \\
\hline Albalá & Albarreal de Tajo & n. d. & Cereal \\
\hline Benquerencia & Toledo & $3.473,64$ & Pastos/cereal \\
\hline Canillas & Toledo & 753,50 & Pastos/cereal \\
\hline Mazaraveda & Toledo & $1.459,91$ & Pastos/cereal \\
\hline Mazarracín & Toledo & 629,64 & Pastos/cereal/huerta \\
\hline Matamoros & Toledo & 329,66 & Pastos \\
\hline Huerta del Capiscol & Toledo & 0,54 & Huerta \\
\hline Ablates y Malagoncillo & Almonacid de Toledo & $1.138,27$ & Pastos/cereal \\
\hline Ablatejos & Toledo & 303,94 & Pastos/cereal \\
\hline Ajofrín (señorío) & Ajofrín & n. d. & Desconocido \\
\hline Ajofrín & Ajofrín & 7,54 & Cereal/viñedo \\
\hline Huerta de los Baños & Ajofrín & n. d. & Huerta \\
\hline Ajofrín (huebras y prados) & Ajofrín & n. d. & Viñedo/pastos \\
\hline Valdemozárabes & Almonacid de Toledo & 932,46 & Pastos/cereal \\
\hline Montalbanejos & Almonacid de Toledo & $1.689,25$ & Pastos/cereal \\
\hline Almorox & Almorox & 7,91 & Cereal \\
\hline Añover & Añover de Tajo & n. d. & Cereal \\
\hline Añover & Añover de Tajo & 64,99 & Cereal \\
\hline Añover (Constanza Hdez.) & Añover de Tajo & 54,16 & Cereal \\
\hline Arcicóllar & Arcicóllar & n. d. & Cereal/viñedo/pastos \\
\hline Regachuelo de Canales & Chozas de Canales & 177,45 & Pastos \\
\hline Cobeja, Alameda, Darageval & Cobeja/Alameda de la Sagra & 1,41 & Cereal/pastos \\
\hline Miguel Martín & El Casar de Escalona & 65,93 & Cereal \\
\hline Esquivias (Santa María) & Esquivias & 36,70 & Viñedo/cereal \\
\hline Esquivias & Esquivias & 18,11 & Cereal \\
\hline Algurilla & Fuensalida & 66,79 & Cereal \\
\hline Renales y Villamocén & Fuensalida & 393,61 & Cereal \\
\hline Hovaniel & Hormigos & 80,53 & Cereal/pastos \\
\hline Hurtada & La Mata & 108,50 & Olivar/cereal \\
\hline Lucillos & Lucillos & 45,21 & Cereal/viñedo \\
\hline Fuente Altamia & Maqueda & 206,27 & Cereal/huerta/pastos \\
\hline Maqueda (Gil de Rojas) & Maqueda & 153,93 & Cereal/viñedo/olivar \\
\hline Azaña & Numancia de la Sagra & n. d. & Viñedo/cereal \\
\hline Azaña & Numancia de la Sagra & 8,52 & Viñedo/cereal \\
\hline Villeriche & Numancia de la Sagra & n. d. & Pastos/cereal \\
\hline Olías & Olías del Rey & 190,63 & Cereal/olivar \\
\hline Alpuébrega & Polán & $1.370,82$ & Pastos \\
\hline Portillo & Portillo de Toledo & 83,64 & Cereal/viñedo/olivar \\
\hline Olivas de Portillo & Portillo de Toledo & n. d. & Olivar \\
\hline Canales & Recas & 144,11 & Cereal/huerta/pastos \\
\hline Higueruela & Santa Olalla & 317,61 & Cereal/pastos \\
\hline Santa Olalla & Santa Olalla & 16,80 & Viñedo/cereal \\
\hline Villamiel & Villamiel de Toledo & 200,05 & Cereal \\
\hline Melgar & Villasequilla & 8,52 & Cereal/pastos \\
\hline Yeles & Yeles & 159,83 & Cereal \\
\hline Yuncler & Yuncler & 53,69 & Cereal/viñedo \\
\hline Superficie total (ha) & & $15.407,35$ & \\
\hline
\end{tabular}

Fuentes: ABCT, Obra y Fábrica, Posesiones, Manual y Protocolos; AHPT, Catastro de Ensenada, Libros de Haciendas del Estado Eclesiástico. Para conversiones de antiguas medidas de superficie al sistema métrico decimal, Cobo (1991: 38-39). 


\section{ANEXO 2}

Rentas de dehesas, de labrantíos y total del cabildo catedralicio de Toledo en maravedíes constantes por hectárea, deflactadas por el índice de precios de Toledo

(IPT) y por el índice de productos agrarios (IPA), 1521-1650

(Números índices, base 100=1521-1529. Medias móviles de 9 años)

\begin{tabular}{|c|c|c|c|c|c|c|}
\hline \multicolumn{3}{|c|}{ Períodos Renta dehesas IPT Renta dehesas IPA } & \multicolumn{4}{|c|}{ Renta labrantíos IPT Renta labrantíos IPA Renta total IPT Renta total IPA } \\
\hline $1521-1529$ & 100,0 & 100,0 & 100,0 & 100,0 & 100,0 & 100,0 \\
\hline $1533-1541$ & 110,3 & 121,1 & 97,9 & 108,1 & 107,3 & 118,1 \\
\hline $1558-1566$ & 123,6 & 127,7 & 119,1 & 123,2 & 122,5 & 126,6 \\
\hline $1579-1587$ & 116,4 & 120,7 & 178,9 & 185,7 & 131,2 & 136,0 \\
\hline $1598-1606$ & 89,1 & 91,7 & 140,9 & 144,4 & 101,3 & 104,1 \\
\hline $1610-1618$ & 78,2 & 80,0 & 155,9 & 159,6 & 96,5 & 98,8 \\
\hline $1615-1623$ & 69,0 & 69,3 & 139,7 & 140,4 & 85,7 & 86,1 \\
\hline $1633-1641$ & 56,5 & 60,2 & 183,5 & 195,9 & 86,4 & 92,2 \\
\hline $1642-1650$ & 42,8 & 42,5 & 129,8 & 128,2 & 63,3 & 62,7 \\
\hline \multicolumn{7}{|c|}{ Variación $(\%)^{*}$} \\
\hline Períodos & \multicolumn{2}{|c|}{ Renta dehesas IPT Renta dehesas IPA } & Renta labrantío & labrant & nta total & nta total IPA \\
\hline $1521-1529$ & - & - & - & - & - & - \\
\hline $1533-1541$ & 10,3 & 21,1 & $-2,1$ & 8,1 & 7,3 & 18,1 \\
\hline $1558-1566$ & 12,1 & 5,4 & 21,7 & 14,0 & 14,2 & 7,3 \\
\hline $1579-1587$ & $-5,8$ & $-5,5$ & 50,2 & 50,7 & 7,0 & 7,4 \\
\hline $1598-1606$ & $-23,4$ & $-24,0$ & $-21,2$ & $-22,2$ & $-22,7$ & $-23,5$ \\
\hline $1610-1618$ & $-12,3$ & $-12,7$ & 10,6 & 10,5 & $-4,8$ & $-5,1$ \\
\hline $1615-1623$ & $-11,7$ & $-13,4$ & $-10,4$ & $-12,0$ & $-11,2$ & $-12,9$ \\
\hline $1633-1641$ & $-18,2$ & $-13,1$ & 31,4 & 39,5 & 0,9 & 7,2 \\
\hline $1642-1650$ & $-24,2$ & $-29,4$ & $-29,3$ & $-34,6$ & $-26,7$ & $-32,0$ \\
\hline
\end{tabular}

*La variación se refiere al periodo inmediatamente anterior.

Fuentes: ABCT, Obra y Fábrica, Carta Cuenta, 1.194-1.234 y libros de los años 1600-1650. 